Check for updates

Cite this: RSC Adv., 2017, 7, 32100

Received 12th June 2017

Accepted 13th June 2017

DOI: $10.1039 / c 7 r a 06540 j$

rsc.li/rsc-advances

\title{
Separation of rare earths and other valuable metals from deep-eutectic solvents: a new alternative for the recycling of used NdFeB magnets $\uparrow$
}

\author{
Sofía Riaño, (D) a Martina Petranikova, (D) ${ }^{\mathrm{b}}$ Bieke Onghena, ${ }^{a}$ Tom Vander \\ Hoogerstraete, (D) a Dipanjan Banerjee, (D) ${ }^{c}$ Mark R. StJ. Foreman, (D) b \\ Christian Ekberg (D) ${ }^{b}$ and Koen Binnemans (D) *a
}

\begin{abstract}
Deep-eutectic solvents (DESs) are used as a promising alternative to aqueous solutions for the recovery of valuable metals from $\mathrm{NdFeB}$ magnets. A deep-eutectic solvent based on choline chloride and lactic acid (molar ratio $1: 2$ ) was used for the leaching of rare earths and other metals from NdFeB magnets. A process for the separation of Fe, B and Co from $\mathrm{Nd}$ and $\mathrm{Dy}$ in the deep-eutectic solvent was developed by using the ionic liquid tricaprylmethylammonium thiocyanate (Aliquat $336 \mathrm{SCN}$, [A336][SCN]) diluted in toluene $(0.9 \mathrm{M})$. The extraction parameters were optimized and stripping of $B$ was efficiently carried out by $\mathrm{HCl}$, while EDTA was employed for the recovery of Fe and Co. The separation of $\mathrm{Nd}$ and Dy was assessed by using two different types of extractants, a mixture of trialkylphosphine oxides (Cyanex 923) and bis(2-ethylhexyl)phosphoric acid (D2EHPA). Based on the distribution ratios, separation factors and the ease of subsequent stripping, Cyanex 923 was chosen as the most effective extractant. The purified Dy present in the less polar phase was easily recovered by stripping with water, while the Nd present in the deep-eutectic solvent was recovered by precipitation stripping with a stoichiometric amount of oxalic acid. $\mathrm{Nd}_{2} \mathrm{O}_{3}$ and $\mathrm{Dy}_{2} \mathrm{O}_{3}$ were recovered with a purity of $99.87 \%$ and $99.94 \%$, respectively. The feasibility to scale up this separation process was corroborated by a setup of mixer-settlers and highlighted by the possibility to fully recover and reuse the deep-eutectic solvent and the less polar phases employed in the extractions. The new proposed system based on a deep-eutectic solvent combined with traditional organic extraction phases presented higher selectivities and efficiencies than the analogous aqueous system. Extended X-ray absorption fine structure (EXAFS) was employed to elucidate the different mechanisms for extraction of $\mathrm{Co}$ and Fe from the deep-eutectic solvent and from an aqueous solution.
\end{abstract}

\section{Introduction}

The recycling of rare-earth permanent magnets continues to be of high importance since it represents a promising strategy against the global supply crisis of rare-earth elements. ${ }^{1}$ During the last years, the environmental and economic benefits of NdFeB magnet recycling have been discussed, analyzed and investigated. ${ }^{2,3}$ Diverse methodologies have been proposed, including the use of mechano-chemical treatment without external heating, ${ }^{4}$ the recovery of neodymium from $\mathrm{NdFeB}$

${ }^{a}$ KU Leuven, Department of Chemistry, Celestijnenlaan 200F, 3001 Heverlee, Belgium. E-mail: Koen.Binnemans@kuleuven.be

${ }^{b}$ Chalmers University of Technology, Nuclear Chemistry and Industrial Materials Recycling, Department of Chemistry and Chemical Engineering, SE-412 96 Gothenburg, Sweden

'Dutch-Belgian Beamline (DUBBLE), ESRF - The European Synchrotron, CS 40220, F38043 Grenoble Cedex 9, France

$\dagger$ Electronic supplementary information (ESI) available. See DOI: 10.1039/c7ra06540j magnets at high temperatures using molten magnesium metal as extractant ${ }^{5}$ and hydrogen gas to separate the $\mathrm{NdFeB}$ magnets from waste..$^{6-9}$ As an alternative to these processes, rare earths and other valuable metals present in magnet scrap can be recovered and purified through leaching and solvent extraction..$^{2,10-12}$ The separation and purification of metals by solvent extraction is a well-known strategy that has been used at laboratory and industrial scale for decades. ${ }^{13-20}$ To start the separation process, a leachate or a concentrate containing the metals of interest must be obtained. With this aim, strong mineral acids and bases, leaching agents such as cyanide or chelating agents are normally used to leach the metals into an aqueous solution that is later processed by solvent extraction. ${ }^{10,21-24}$ The metal ions are extracted into an organic phase that usually consists of an extractant, a molecular solvent, and if needed, a phase modifier (to avoid the formation of a third phase and/or to improve phase disengagement). ${ }^{16}$ In the cases where nontarget metals are co-extracted together with the desired metals, scrubbing can be done to improve the purity of the 
previously obtained raffinate. The metal ions can be back extracted from the organic phase using an appropriate stripping agent. Afterwards, they can be precipitated and calcined to obtain metal oxides.

In solvent extraction, attention has been paid to the replacement of commonly used organic solvents. New organic phases that provide new and tunable functionalities to improve the selectivity and efficiency of the extraction process are preferred, especially when they benefit workplace safety and are less harmful to the environment. With this aim, ionic liquids have been successfully employed as an organic phase in solvent extraction for the purification of metal ions, including transition metals and rare-earth elements. ${ }^{10-12,25-32}$ In contrast, less effort has been made in order to replace the aqueous phase by other liquid media able to facilitate the separation process. Deep-eutectic solvents (DESs) could act as a new functionalized, more polar phase for the leaching, solvent extraction, separation and purification of metal ions. ${ }^{33-36}$

DESs are systems formed from a eutectic mixture of Lewis or Brønsted acids and bases which can contain a variety of anionic and/or cationic species. ${ }^{35}$ DESs have been defined by Abbott et al. ${ }^{37}$ with the general formula $\mathrm{R}_{1} \mathrm{R}_{2} \mathrm{R}_{3} \mathrm{R}_{4} \mathrm{~N}^{+} \mathrm{X}^{-} \cdot \mathrm{Y}$ and can be classified into four different groups: (1) type I, in which $\mathrm{Y}$ corresponds to $\mathrm{ZnCl}_{2}, \mathrm{SnCl}_{2}, \mathrm{AlCl}_{3}, \mathrm{GaCl}_{3}, \mathrm{FeCl}_{3}$; (2) type II, in which hydrated metal halides are used as for instance $\mathrm{Y}=$ $\mathrm{MCl}_{x} \cdot y \mathrm{H}_{2} \mathrm{O}, \mathrm{M}=\mathrm{Cr}, \mathrm{Co}, \mathrm{Cu}, \mathrm{Ni}, \mathrm{Fe}$; (3) type III, in which $\mathrm{Y}$ is an hydrogen bond donor (HBD) that can be an amide, alcohol or carboxylic acid; (4) type IV, in which DESs are composed of metal chlorides mixed with HBDs such us urea, ethylene glycol, acetamide or hexanediol. DESs are structurally different from ionic liquids (ILs) which are composed entirely by ions and usually contain only one type of anion and cation. ${ }^{35,38}$ Ionic liquids and DESs share some common physical properties such as low vapor pressure and non-flammability. Besides these properties, DESs are easier and cheaper to prepare than ionic liquids since their synthesis relies on the mixture of two components which is $100 \%$ atom economic (beneficial for their scaling up and industrial use). Moreover, DESs have excellent dissolution properties due to their ability to donate or accept electrons or protons to form hydrogen bonds. ${ }^{35,38}$ DESs are able to selectively dissolve various metal oxides depending on the deep eutectic solvent that is employed. ${ }^{33,39}$ This makes DESs good candidates for the dissolution of end-of-life $\mathrm{NdFeB}$ magnets. The composition of a NdFeB magnet varies depending on the type of application it is used for. Generally, cobalt is added to the magnets to increase the Curie temperature, while dysprosium and gadolinium are added when the magnets have to be used at high temperatures as these elements increase the coercivity of the magnet. ${ }^{40,41}$ Praseodymium is often present together with neodymium to reduce production costs since its complete separation from neodymium requires multiple steps and these two elements share similar magnetic properties. ${ }^{42}$

In this paper the preparation of a $\mathrm{NdFeB}$ magnet leachate with a deep-eutectic solvent (choline chloride and lactic acid, molar ratio $1: 2$ ) and a subsequent solvent extraction procedure for the separation of neodymium, dysprosium, iron, cobalt and boron from the leachate in two steps are reported for the first time. This DES was chosen because its components are easily available and the protons present in the lactic acid can react with the metal oxides to dissolve them. In the first step, the ionic liquid [A336][SCN] diluted in toluene $(0.9 \mathrm{M})$ is employed for the extraction of iron, cobalt and boron. Afterwards, Cyanex 923 diluted in toluene $(0.9 \mathrm{M})$ is employed for the separation of neodymium and dysprosium. One of the main advantages of this process is that the leaching can be carried out using a cheap and easily available solvent that can be re-used or easily discarded since its components are biodegradable. Moreover, higher distribution ratios are obtained when extracting from deep-eutectic solvent media than from conventional aqueous feeds. The system is versatile. First, only the transition metals and boron are separated and afterwards, dysprosium can be separated. Neodymium remaining in the deep-eutectic solvent can be easily stripped. The feasibility of the proposed extraction was tested in larger scale by using a mixer-settler setup.

\section{Experimental}

Information concerning the chemicals and the equipment can be found in the ESI. $\dagger$

\section{Synthesis of DES}

Batches of approximately 1 liter of DES based on choline chloride and lactic acid as hydrogen bond donor were prepared by mixing choline chloride ( 1 molar eq.) and lactic acid ( 2 molar eq.) and shaking manually in a bottle until the mixture was completely homogeneous. Viscosity of the DES at $25^{\circ} \mathrm{C}$ was 156 cP, water content: $13 \mathrm{wt} \%$.

\section{Leaching}

Two different samples of small $\mathrm{NdFeB}$ magnets (one roundshaped of approximately $25 \mathrm{D} \times 10 \mathrm{H} \mathrm{mm}$ and one rectangularshaped of approximately $25 \mathrm{~W} \times 10 \mathrm{H} \times 33 \mathrm{~L} \mathrm{~mm}$ ) were kindly provided by BEC Gesellschaft für Produktmanagement GmbH (Moers, Germany) and Magneti Ljubljana (Ljubljana, Slovenia), respectively. The magnets were demagnetized by heating them during $5 \mathrm{~h}$ at $300{ }^{\circ} \mathrm{C}$ in a furnace. Afterwards, they were crushed, milled and sieved to collect the fraction $<400 \mu \mathrm{m}$ from which a part was further ball-milled and sieved to obtain the $<100 \mu \mathrm{m}$ fraction. The chemical composition of the magnet samples was determined by carefully dissolving a sample of the magnet powder in concentrated hydrochloric acid and quantifying the solution with ICP-OES (Table S1, ESI $\dagger$ ). For the roasting process, a magnet powder sample of $5 \mathrm{~g}$ was placed in a porcelain crucible without lid and heated at $950{ }^{\circ} \mathrm{C}$ in a muffle furnace during $15 \mathrm{~h}$.

Magnet samples of $100 \mathrm{mg}$ were dissolved in $5 \mathrm{~mL}$ of deepeutectic solvent and heated at $70{ }^{\circ} \mathrm{C}$ during $12 \mathrm{~h}$, unless stated otherwise. Afterwards, the leachate was centrifuged and filtered. A sample of the leachate was diluted with $1 \mathrm{M} \mathrm{HNO}_{3}$ and the metal concentration was measured with ICP-OES. The solid residue was dissolved in $6 \mathrm{M} \mathrm{HNO}_{3}$ and quantified by ICPOES. 


\section{Solvent extraction}

The chloride ion in the ionic liquid Aliquat 336 was exchanged by a thiocyanate anion by equilibrating it three times with a 2.5 M KSCN solution. Afterwards, the thiocyanate ionic liquid was washed. For the solvent extraction experiments, a synthetic solution was prepared by dissolving $\mathrm{NdCl}_{3} \cdot 6 \mathrm{H}_{2} \mathrm{O}, \mathrm{DyCl}_{3} \cdot 6 \mathrm{H}_{2} \mathrm{O}$, $\mathrm{CoCl}_{2} \cdot 6 \mathrm{H}_{2} \mathrm{O}, \mathrm{FeCl}_{3}$ and $\mathrm{H}_{3} \mathrm{BO}_{3}$ in the DES and stirring the mixture while heating at $40{ }^{\circ} \mathrm{C}$. The final concentrations \pm the standard deviation were: $0.016 \mathrm{M}$ for $\mathrm{Nd}, 0.122 \mathrm{M}$ for $\mathrm{Fe}$, $0.0054 \mathrm{M}$ for $\mathrm{B}, 0.0007 \mathrm{M}$ for Dy and $0.0026 \mathrm{M}$ for Co. These concentrations mimic an average of the composition of different leachates of NdFeB magnets. For the removal of iron, cobalt and boron, batch experiments were carried out by contacting $1 \mathrm{~mL}$ of DES with $1 \mathrm{~mL}$ of the less polar phase [A336] [SCN] diluted in toluene $(0.9 \mathrm{M})$ in closed $4 \mathrm{~mL}$ vials. The vials were shaken at $25{ }^{\circ} \mathrm{C}$ and $2000 \mathrm{rpm}$ during $20 \mathrm{~min}$, unless otherwise is stated. Viscosity of the of the less polar phase [A336][SCN] diluted in toluene $(0.9 \mathrm{M})$ at $25^{\circ} \mathrm{C}$ was $6.1 \mathrm{cP}$. Batch experiments for the separation of $\mathrm{Nd}$ and Dy were carried out using a synthetic solution which was prepared by dissolving $\mathrm{NdCl}_{3} \cdot 6 \mathrm{H}_{2} \mathrm{O}$ and $\mathrm{DyCl}_{3} \cdot 6 \mathrm{H}_{2} \mathrm{O}$ in the deep-eutectic solvent (choline chloride and lactic acid, molar ratio $1: 2$ ). The final concentrations \pm the standard deviation were $0.016 \mathrm{M}$ for $\mathrm{Nd}$ and $0.0007 \mathrm{M}$ for Dy. A sample of $1 \mathrm{~mL}$ of this solution was put in contact with $1 \mathrm{~mL}$ of less polar phase (Cyanex 923 or D2EHPA diluted in toluene $0.9 \mathrm{M}$ unless otherwise is stated) and shaken during $20 \mathrm{~min}$ at $25{ }^{\circ} \mathrm{C}$ and $2000 \mathrm{rpm}$. For the stripping experiments, the loaded less polar phase was put in contact with 1 $\mathrm{mL}$ of stripping agent (different concentrations of $\mathrm{HCl}$, oxalic acid, citric acid or EDTA) in $4 \mathrm{~mL}$ closed vials, and shaken during $60 \mathrm{~min}$ at $25{ }^{\circ} \mathrm{C}$. A sample of the aqueous phase was taken, diluted and measured with ICP-OES.

For comparison reasons, solvent extraction experiments from aqueous solutions containing $0.015 \mathrm{M}$ for $\mathrm{Nd}, 0.114 \mathrm{M}$ for $\mathrm{Fe}$, $0.0061 \mathrm{M}$ for B, 0.0006 $\mathrm{M}$ for Dy and $0.0025 \mathrm{M}$ for Co were carried out. $\mathrm{CaCl}_{2}$ was used as source of chlorides and its concentration in the aqueous phase was $1.5 \mathrm{M}$, unless otherwise stated. For the separation of $\mathrm{Nd}$ and Dy the concentrations in the aqueous phase were $0.015 \mathrm{M}$ for $\mathrm{Nd}$ and $0.0007 \mathrm{M}$ for Dy. The extraction was carried out in $4 \mathrm{~mL}$ vials at $25^{\circ} \mathrm{C}$ and $2000 \mathrm{rpm}$ during $60 \mathrm{~min}$ to assure that equilibrium was achieved.

A counter-current mixer-settler system comprised of five extraction units (PVDF) was used to evaluate the scaling up feasibility of the developed process for the separation of iron, cobalt and boron from neodymium and dysprosium and subsequently dysprosium from neodymium. The mixer-settler unit consists of: (a) the mixing chamber, where the less polar phase and the more polar phase are mixed using a motor stirrer, (b) the settling chamber, where the phases are separated by density difference and (c) a more polar phase outlet compartment, from which the more polar phase exits the unit. ${ }^{43}$ The more and less polar phases were pumped into the mixer-settlers using electromagnetic pumps (Iwaki). Each mixer-settler unit has a volume of $120 \mathrm{~mL}$ per unit (MYMEKO, Sweden).

The light phase : heavy phase ratio (LP : HP) was $1: 1$. The light phase corresponds to $0.9 \mathrm{M}$ [A336][SCN] or Cyanex 923 in toluene, while the heavy phase corresponds to the DES chlorine chloride : lactic acid (molar ratio $1: 2$ ). The flow rates for the deep-eutectic solvent and organic feeds were $1.5 \mathrm{~mL} \mathrm{~min}^{-1}$, the mixing speed in the mixer chambers was $900 \mathrm{rpm}$. For the separation of dysprosium from neodymium, the LP : HP phase ratio was $2: 1$. The flow rates for the deep eutectic solvent and organic feeds were 3 and $1.5 \mathrm{~mL} \mathrm{~min}^{-1}$, respectively, the mixing speed in the mixer chambers was $900 \mathrm{rpm}$.

\section{EXAFS}

Extended X-ray Absorption Fine Structure (EXAFS) spectra of the Fe K-edge (7112 eV) and Co K-edge (7709 eV) were collected at the Dutch-Belgian Beamline (DUBBLE, BM26A) at the European Synchrotron Radiation Facility (ESRF) in Grenoble (France). The energy of the X-ray beam was tuned by a double-crystal monochromator operating in fixed-exit mode using a Si(111) crystal pair. The measurements were done in transmission mode using ionization chambers filled with $\mathrm{Ar} / \mathrm{He}$ gas at ambient pressure. A brass sample holder with Kapton ${ }^{\circledR}$ windows and a flexible polymeric spacer (VITON®) with a thickness of $2 \mathrm{~mm}$ was used as a sample holder. Samples of the less polar phase (0.9 M [Aliquat 336][SCN]) were taken after equilibrating it with solutions of approximately $0.09 \mathrm{M}$ of $\mathrm{Fe}$ and $0.08 \mathrm{M}$ of Co in DES. For the aqueous solutions the same concentrations of $\mathrm{Fe}$ and Co were employed and the total concentration of $\mathrm{CaCl}_{2}$ was $5 \mathrm{M}$. Standard procedures were used for pre-edge subtraction and data normalization in order to isolate the EXAFS function $(\chi)$. The isolated EXAFS oscillations were accomplished by a smoothing spline as realized in the program VIPER. ${ }^{44}$ The data were fitted using the ab initio code FEFF 7.0 which was used to calculate the theoretical phase and amplitude functions that subsequently were used in the non-linear least-squares refinement of the experimental data. ${ }^{45}$ The chloride concentration in both phases was determined with a bench top total reflection X-ray fluorescence (TXRF) spectrometer (S2 Picofox, Bruker). X-ray diffraction powder patterns were recorded at room temperature with a Seifert $3003 \mathrm{~T} / \mathrm{T}$ X-ray diffractometer equipped with a scintillation detector. X-ray type: $\mathrm{Cu} \mathrm{K}_{\alpha}$ operating at $40 \mathrm{kV}$ and $40 \mathrm{~mA}$, scanning range: $10-80^{\circ}(2 \theta)$, step width: $0.02^{\circ}$, step scan: $2.00 \mathrm{~s}$. The $\mathrm{X}-$ ray diffractograms were processed by "X'pert HighScore Plus" PANalytical software with ICDD database.

\section{Results and discussion}

\section{Dissolution}

For the dissolution experiments, two NdFeB magnets were tested. Both magnets contained four different rare earths, Nd, Dy, Pr and Gd. Magnet 2 contained higher amounts of Gd and Pr but a lower amount of Dy compared to magnet 1 .

The percentage metal leached $(\% L)$ was calculated as follows,

$\% L=\frac{\text { amount of metal in the leachate }}{\text { total amount of metal in the leachate and precipitate }} \times 100$ 
To the best of our knowledge, the solubility of rare-earth oxides has not been reported in any DESs yet. Magnet samples $(<100 \mu \mathrm{m}$ particle size $)$ were roasted and leached using three different deep-eutectic solvents based on choline chloride (ChCl), ChCl: urea, $\mathrm{ChCl}$ : ethylene glycol and $\mathrm{ChCl}$ : lactic acid, all of them with a molar ratio $1: 2$. High $\% L$ were obtained when using the deep-eutectic solvent composed of $\mathrm{ChCl}$ : lactic acid $(1: 2)$ and no significant deviations were obtained between both roasted magnets. The mixtures $\mathrm{ChCl}$ : urea $(1: 2)$ and $\mathrm{ChCl}$ : ethylene glycol $(1: 2)$ allowed the poor dissolution of $\mathrm{Nd}$ and Fe and did not dissolve any of the other metal oxides from the roasted magnets. Since physicochemical properties of deepeutectic solvents depend on the kind of moieties and substituents present in the mixture, the high solubility of the oxides in the choline chloride : lactic acid $(1: 2)$ DES can be explained by the fact that the protons present in the lactic acid react with the oxides to form water (eqn (2)) and probably the coordinating abilities of lactic acid and the choline help dissolution.

$$
\begin{aligned}
\mathrm{Nd}_{2} \mathrm{O}_{3(\mathrm{~s})}+6 \mathrm{CH}_{3} \mathrm{CHOHCOOH}_{(\mathrm{DES})} \rightarrow \\
2 \mathrm{Nd}\left(\mathrm{CH}_{3} \mathrm{CHOHCOO}\right)_{3(\mathrm{DES})}+3 \mathrm{H}_{2} \mathrm{O}_{(\mathrm{DES})}
\end{aligned}
$$

Since the best results were obtained with the DES based on choline chloride and lactic acid $(1: 2)$, it was decided to carry out the dissolution of metals from the NdFeB magnets with this solvent. The effect of the liquid : solid $(\mathrm{L} / \mathrm{S})$ ratio on the two different roasted magnet powders was investigated (Fig. 1).

As expected, the percentage of metal leached increased when using $\mathrm{L} / \mathrm{S}$ ratios larger than $20 \mathrm{~mL} \mathrm{~g}^{-1}$. When trying to dissolve the magnet using lower quantities of DES, low \% $L$ values were obtained. This can be explained because of the poor agitation due to the low amount of liquid and the large amount of solid, which probably makes it difficult for the DES to reach all the metals in the magnet powder. At high L/S ratios, all metals were dissolved almost completely. No selectivity was observed at any ratio and there were not significant differences when using magnets with different compositions.

The effect of the water content in the DES choline chloride : lactic acid $(1: 2)$ on the percentage of metal leached was evaluated (Fig. 2).

The effect of roasting the magnets was investigated by comparing the leaching of non-roasted and roasted magnets. The magnet powders $(<100 \mu \mathrm{m}$ particle size $)$ were roasted at $950{ }^{\circ} \mathrm{C}$ before dissolving them in the DES at $70{ }^{\circ} \mathrm{C}$ during $24 \mathrm{~h}$. In the case of non-roasted magnets $(<100 \mu \mathrm{m}$ particle size $)$, the dissolution was started by contacting the non-roasted magnets with DES. We point out as a safety note that the addition of non-roasted magnet to the DES should be done slowly in an open vial since evolution of hydrogen can take place (eqn (3)).

$$
\begin{aligned}
& 2 \mathrm{Nd}_{(\mathrm{s})}+6 \mathrm{CH}_{3} \mathrm{CHOHCOOH}_{(\mathrm{DES})} \rightarrow \\
& \quad 2 \mathrm{Nd}\left(\mathrm{CH}_{3} \mathrm{CHOHCOO}\right)_{3(\mathrm{DES})}+3 \mathrm{H}_{2(\mathrm{~g})}
\end{aligned}
$$

For the dissolution of the non-roasted magnet with the DES choline chloride : lactic acid ( $1: 2)$, an increase in water content (up to $60 \mathrm{wt} \%$ ) had no significant effect on the percentage metal
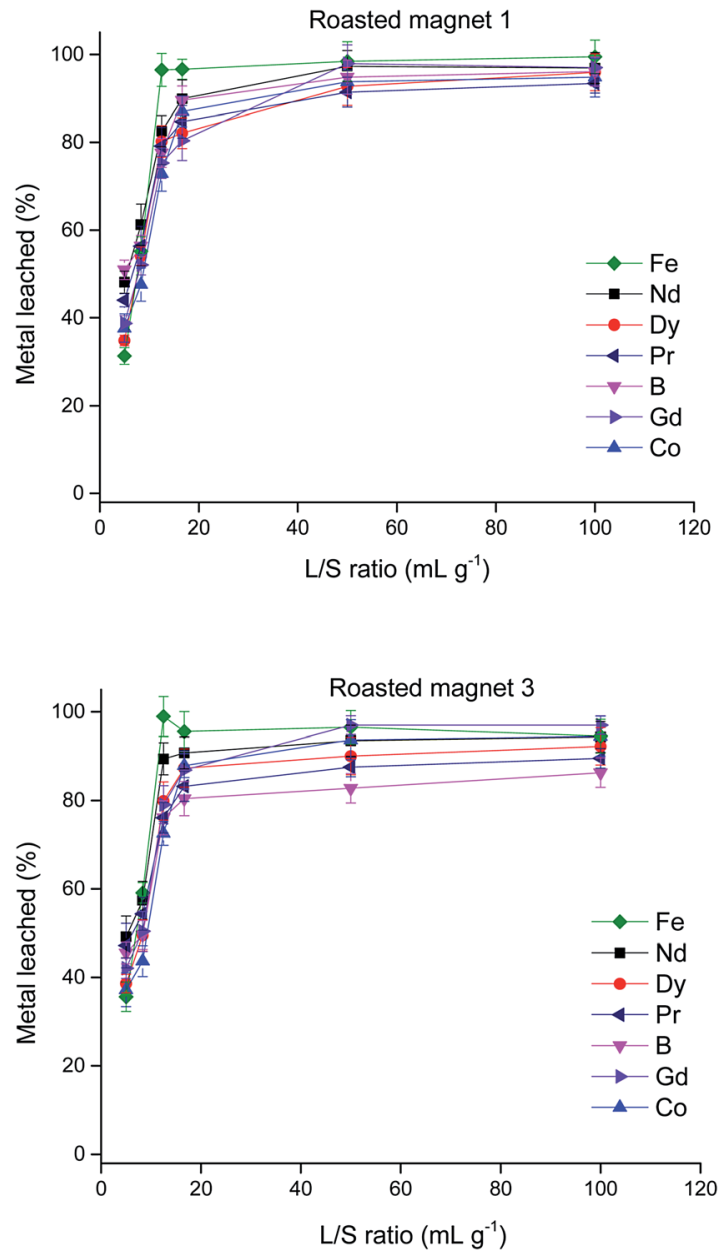

Fig. 1 Effect of the liquid: solid ratio $(L / S)$ on the percentage metal leached from two different roasted magnet powders $(<100 \mu \mathrm{m}$ particle size), $70{ }^{\circ} \mathrm{C}$ leaching temperature, $24 \mathrm{~h}$ leaching duration.

leached. As expected, no dissolution of metals occurred when pure water was used.

For the leaching of the roasted magnets, selectivity can be achieved when adding water to the DES (Fig. 2). During the roasting process, different kinds of metal oxides such as $\mathrm{Fe}_{2} \mathrm{O}_{3}$, $\mathrm{NdBO}_{3}$ and $\mathrm{NdFeO}_{3}$ are formed. ${ }^{46}$ In the same way as explained in eqn (2), lactic acid reacts with the corresponding oxides to form water (eqn (4)):

$$
\begin{aligned}
& \mathrm{Fe}_{2} \mathrm{O}_{3}+6 \mathrm{CH}_{3} \mathrm{CHOHCOOH}_{(\mathrm{DES})} \rightarrow \\
& \quad 2 \mathrm{Fe}\left(\mathrm{CH}_{3} \mathrm{CHOHCOO}\right)_{3(\mathrm{DES})}+3 \mathrm{H}_{2} \mathrm{O}
\end{aligned}
$$

In the case of non-roasted magnets, iron is released into the DES as iron(II), as follows,

$$
\begin{aligned}
& \mathrm{Fe}_{(\mathrm{s})}+2 \mathrm{CH}_{3} \mathrm{CHOHCOOH}(\mathrm{DES}) \\
& \quad \mathrm{Fe}\left(\mathrm{CH}_{3} \mathrm{CHOHCOO}\right)_{2(\mathrm{DES})}+\mathrm{H}_{2(\mathrm{~g})}
\end{aligned}
$$

Iron(II) is more stable against hydrolysis than iron(III), thus, in the case of non-roasted magnets, no selectivity can be achieved since iron(II) can go in solution as long as there is not an oxidizing environment. In the case of roasted magnets (eqn (4)), 

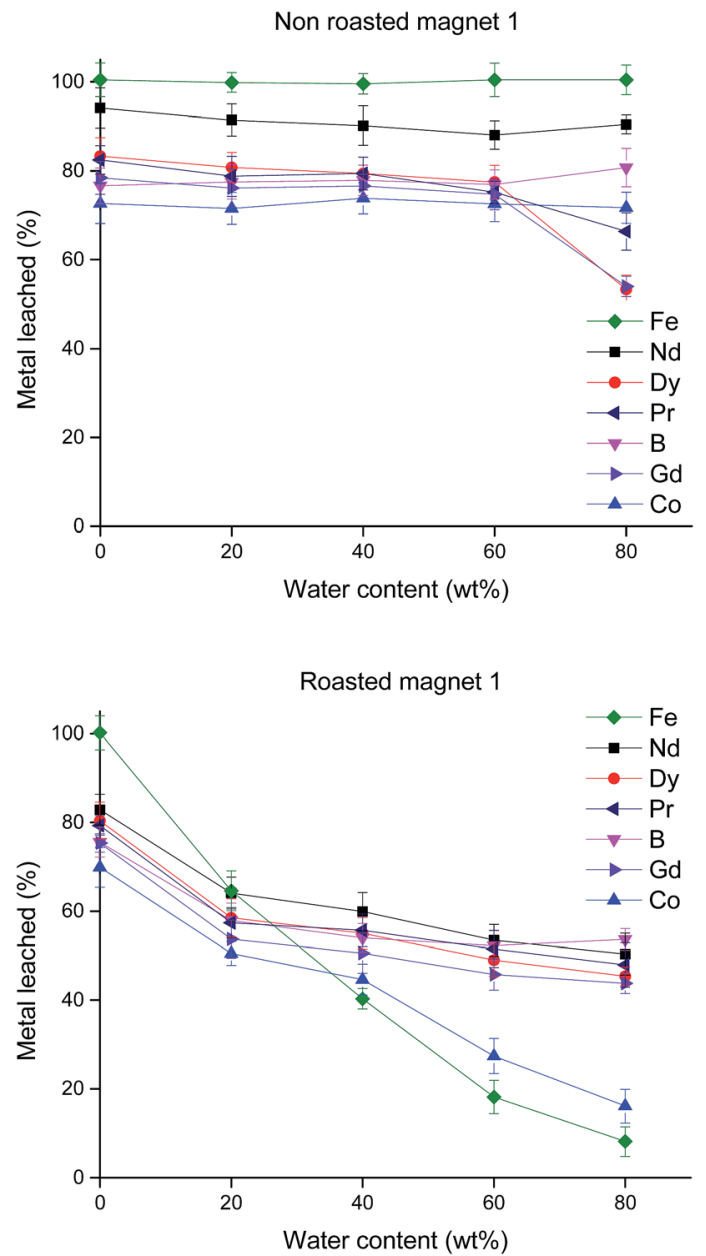

Fig. 2 Effect of the water content (wt\%) in the deep-eutectic solvent choline chloride : lactic acid (1:2) on the percentage metal leached from non-roasted ( $<100 \mu \mathrm{m}$ particle size) and roasted NdFeB magnet 1 ( $<100 \mu \mathrm{m}$ particle size), leaching temperature: $70{ }^{\circ} \mathrm{C}, 24 \mathrm{~h}$ leaching duration, $\mathrm{L} / \mathrm{S}=12.5 \mathrm{~mL} \mathrm{~g}^{-1}$.

as the lactic acid is consumed and water is produced, the $\mathrm{pH}$ increases allowing the hydrolysis of iron(III) and precipitation of $\mathrm{Fe}(\mathrm{OH})_{3}$. The advantage of such situation is not only the selectivity but also that the eutectic mixture is not decomposed since no redox reactions occur upon dissolution of the roasted magnets. The dissolution of magnets in mixtures of water and DESs is promising and might result after optimizing some leaching parameters (e.g. kinetics, temperature, nature of the carboxylic acid in the DES) in leachates containing mostly rare earths. Still, since the highest $\% L$ was achieved with the DES choline chloride : lactic acid $(1: 2)$ without the addition of water, this DES was employed as the more polar phase for the further solvent extractions.

\section{Solvent extraction}

The leachate from the roasted magnet produced with the DES choline chloride : lactic acid $(1: 2)$ without water was employed as the more polar phase for solvent extraction. Foreman has studied the solvent extraction of transition metals and lanthanides from DES using Aliquat 336 and D2EHPA diluted in an aromatic solvent and a saturated aliphatic hydrocarbon respectively. ${ }^{36}$ Since the recovery of metals from $\mathrm{NdFeB}$ magnets using DES has not been widely explored yet, it was decided to carry out the separation of only the most typical elements present in $\mathrm{NdFeB}$ magnets (i.e. $\mathrm{Nd}$, Dy, Fe, B, Co) through solvent extraction.

To evaluate and quantify the efficiency of the solvent extraction, parameters such as, percentage extraction (\%E), distribution ratio $(D)$ and separation factor $\left(\mathrm{SF}_{\mathrm{A}, \mathrm{B}}\right)$ were evaluated. The percentage extraction $(\% E)$ is defined as the initial amount of metal ion in the more polar phase $\left([\mathrm{M}]_{\mathrm{i}}\right)$ minus the amount of metal ion in the more polar phase after extraction $\left([\mathrm{M}]_{\mathrm{f}}\right)$ over the initial amount of metal ion $\left([\mathrm{M}]_{\mathrm{i}}\right)$. In case of equal volumes it can be expressed as:

$$
\% E=\frac{[\mathbf{M}]_{\mathrm{i}}-[\mathbf{M}]_{\mathrm{f}}}{[\mathbf{M}]_{\mathrm{i}}} \times 100
$$

The distribution ratio $(D)$ of a metal is defined in eqn (7) as the ratio of its concentration in the less polar phase by its concentration in the more polar phase $\left([\mathrm{M}]_{\mathrm{f}}\right)$ after extraction and phase separation.

$$
D=\frac{[\mathbf{M}]_{\mathrm{i}}-[\mathbf{M}]_{\mathrm{f}}}{[\mathbf{M}]_{\mathrm{f}}}
$$

The separation factor $\left(\mathrm{SF}_{\mathrm{A}, \mathrm{B}}\right)$ between two metals is the ratio of the distribution ratios of the metals $\mathrm{A}$ and $\mathrm{B}$, where $\mathrm{A}$ and $\mathrm{B}$ are chosen so that $\mathrm{SF}>1$ (eqn (8)).

$$
\mathrm{SF}=\frac{D_{\mathrm{A}}}{D_{\mathrm{B}}}
$$

Ionic liquids were chosen as the less polar phase for the solvent extraction because they are effective extractants for metal ions. ${ }^{10-12,26,28,31,32}$ Since the available mixer settlers operated exclusively at room temperature, ionic liquids were diluted with organic solvents to avoid longer equilibration times due to the relatively high viscosities. Toluene and Solvent 70 (one of the fractions of kerosene) were tested because they are very common diluents for solvent extraction systems. ${ }^{47-54}$ Despite the fact that toluene is not a green solvent, ${ }^{55}$ it was chosen as diluent since it allowed higher separation factors as well as faster and better phase disengagements in comparison to solvent 70. Besides this, no problems with third phase formation were encountered when using toluene.

Table 1 shows the results obtained for the extraction of $\mathrm{Nd}$, $\mathrm{Fe}, \mathrm{B}$, Dy and Co from a synthetic solution, mimicking the concentrations of a leachate of $\mathrm{NdFeB}$ magnet, where two ionic liquids (Aliquat 336 with two different anions, chloride and thiocyanate, diluted in toluene) were employed.

Both [A336][SCN] and [A336][Cl] extracted Fe and higher distribution ratios were obtained for $\mathrm{B}$ when $[\mathrm{A} 336][\mathrm{Cl}]$ was employed, while [A336][SCN] allowed a more efficient extraction of Co. In both cases, there was almost no extraction of the rare earths. Since in general, high $D$ were obtained for Co with less 
Table 1 Distribution ratios $D$ of neodymium, dysprosium, iron, boron and cobalt $^{a}$

\begin{tabular}{lcc}
\hline & $\begin{array}{c}D \text { for }[\mathrm{A336}][\mathrm{Cl}] \\
\text { in toluene }(0.7 \mathrm{M})\end{array}$ & $\begin{array}{c}D \text { for }[\mathrm{A336}][\mathrm{SCN}] \\
\text { in toluene }(0.7 \mathrm{M})\end{array}$ \\
\hline $\mathrm{Nd}$ & $0.041 \pm 0.009$ & $0.029 \pm 0.006$ \\
$\mathrm{Fe}$ & $187 \pm 6$ & $47.8 \pm 0.7$ \\
$\mathrm{~B}$ & $2.73 \pm 0.30$ & $0.78 \pm 0.08$ \\
$\mathrm{Dy}$ & $0.023 \pm 0.005$ & $0.026 \pm 0.007$ \\
$\mathrm{Co}$ & $0.74 \pm 0.07$ & $192 \pm 10$
\end{tabular}

${ }^{a}$ Shaking time: $60 \mathrm{~min}, 2000 \mathrm{rpm}, 25{ }^{\circ} \mathrm{C}$. Each value represents the average of three measurements. Concentrations in the aqueous phase: $16 \mathrm{mM} \mathrm{Nd}, 122 \mathrm{mM}$ Fe, $5.4 \mathrm{mM} \mathrm{B}, 0.7 \mathrm{mM}$ Dy and $2.6 \mathrm{mM}$ Co.

co-extraction of the rare earths when using [A336][SCN], this extractant was chosen to carry out the first separation stage.

In terms of equilibration time, it was found that a period between 15 and $20 \mathrm{~min}$ was adequate to reach equilibrium. An equilibration time of $20 \mathrm{~min}$ was chosen as the optimal time to make sure that equilibrium was reached. This relatively long equilibration time is needed because of the slow mass transfer process occurring under the operating conditions.

Dilutions of [A336][SCN] in toluene were prepared in order to optimize the concentration of the extractant. Poor phase mixing and slow phase disengagement were observed when working with concentrations of $[\mathrm{A} 336][\mathrm{SCN}]$ higher than $0.9 \mathrm{M}$. A concentration of $0.9 \mathrm{M}$ of [A336][SCN] in toluene was chosen as optimal since it allowed the highest $D$ for B, Fe and Co without facing problems with viscosity. It is important to notice that little if any extraction of the rare earths during this step (Fig. 3).

As chloride is a good inner-sphere ligand it is possible to generate extractable chlorometallate complexes as expressed as follows,

$$
\mathrm{M}^{n+}+n \mathrm{Cl}^{-}+\overline{m[\mathrm{~A} 336]} \rightleftharpoons \overline{\left[\mathrm{MCl}_{n}\right][\mathrm{A} 336]_{m}}
$$

The equilibrium constant can be expressed as

$$
K_{\mathrm{eq}}=\frac{\overline{\left[\mathrm{MCl}_{n}\right][\mathrm{A} 336]_{m}}}{\left[\mathrm{M}^{n+}\right]\left[\mathrm{Cl}^{-}\right]^{n}[\mathrm{~A} 336]^{m}}=\frac{D_{\mathrm{M}}}{\left[\mathrm{Cl}^{-}\right]^{n}[\mathrm{~A} 336]^{m}}
$$

By plotting $\log D$ vs. $\log [\mathrm{A} 336]$ when the chloride concentration is constant, it is possible to determine the number of molecules of ionic liquid that are involved in the extraction of the metal ion (eqn (11)).

$$
\log D=m \log [\mathrm{A} 336]+n \log \left[\mathrm{Cl}^{-}\right]+\log K_{\text {eq }}
$$

It can be seen that the distribution ratios for $\mathrm{B}, \mathrm{Fe}$ and $\mathrm{Co}$ increase with the [A336][SCN] concentration. The distribution ratios of $\mathrm{Co}$ and $\mathrm{Fe}$ are in concordance with what has been reported previously for the extraction of these metals from the same DES. ${ }^{36}$ The stoichiometric ratios between Fe, B and Co and the extractant were determined by plotting the $\log D v s . \log$ $[[\mathrm{A} 336][\mathrm{SCN}]]$ and then doing the linear regression to determine the stoichiometric ratio between the metal ion and the

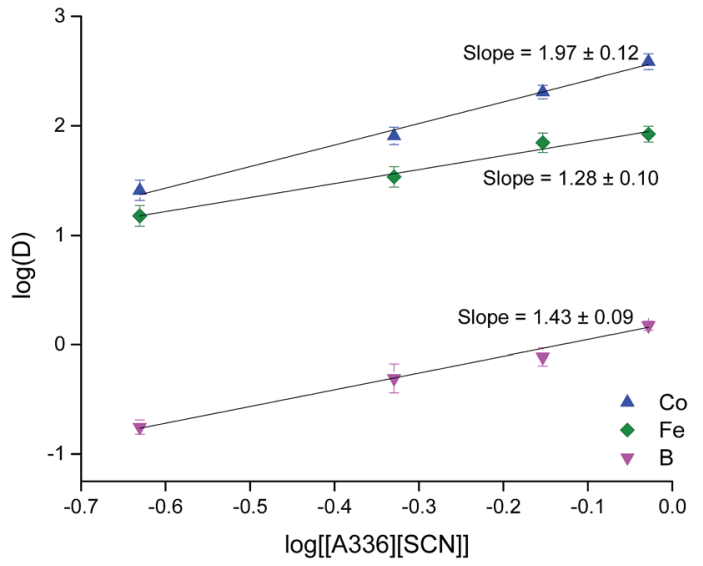

Fig. 3 Effect of the concentration of [A336][SCN] in toluene on the extraction of $\mathrm{Fe}, \mathrm{B}$ and $\mathrm{Co}$ from a mixture of $\mathrm{Nd}, \mathrm{Dy}, \mathrm{Fe}, \mathrm{B}$ and $\mathrm{Co}$ in the DES choline chloride : lactic acid (molar ratio $1: 2$ ). Concentrations in the aqueous phase: $16 \mathrm{mM} \mathrm{Nd}, 122 \mathrm{mM} \mathrm{Fe}, 5.4 \mathrm{M} \mathrm{B}, 0.7 \mathrm{mM}$ Dy and $2.6 \mathrm{mM}$ Co. Shaking speed: $2000 \mathrm{rpm}$ at $25^{\circ} \mathrm{C}$, equilibration time: $20 \mathrm{~min}$. Concentration of $[\mathrm{A} 336][\mathrm{SCN}]=0.2-0.9 \mathrm{M}$.

extractant (Fig. 3). The results show that the slope values are close to 2 for Co and B and 1 for Fe, this would suggest that the complexes formed could correspond to $\left[\mathrm{FeCl}_{4}\right][\mathrm{A} 336]$ and $\left[\mathrm{CoCl}_{4}\right][\mathrm{A} 336]_{2}$. In the case of boron, a value of 1.43 was obtained for the slope, indicating that most likely more than one kind of complex is formed. It is known that boric acid can form $1: 1$ or $1: 2$ anionic complexes with lactic acid, $\left[\mathrm{B}(\mathrm{OH})_{2}\left(\mathrm{C}_{4} \mathrm{H}_{5} \mathrm{O}_{3}\right)\right]^{-}$or $\left[\mathrm{B}\left(\mathrm{C}_{4} \mathrm{H}_{5} \mathrm{O}_{3}\right)_{2}\right]^{-}{ }^{-56}$ In the presence of an excess of lactic acid, the complex $\left[\mathrm{B}\left(\mathrm{C}_{4} \mathrm{H}_{5} \mathrm{O}_{3}\right)_{2}\right]^{-}$would be predominant. This complex could be extracted by the ionic liquid present in the less polar phase as $\left[\mathrm{B}\left(\mathrm{C}_{4} \mathrm{H}_{5} \mathrm{O}_{3}\right)_{2}\right][\mathrm{A} 336]$. However, estimations by slope analysis do not give complete information about the structure of the extracted metal complex. EXAFS was used to determine the environment of the extracted complexes of Fe and Co and the results will be discussed in the section EXAFS.

Since industrial processes using ambient temperature are usually less expensive and preferred over those that use high temperatures, the effect of the temperature was not studied. However, it must be stressed that working at higher temperatures could help to reduce the viscosity of the system and thus, to increase the mass transfer of the extraction process. Additionally, it could also allow the use of the ionic liquid in its undiluted form, which will possibly increase the extraction of boron.

After the removal of $\mathrm{Fe}$, Co and B (i.e. by countercurrent solvent extraction in mixer settlers), a process for the separation of $\mathrm{Nd}$ and Dy present in the DES was developed. Two conventional extractants were tested: Cyanex 923 and D2EHPA. D2EHPA is a well-known acidic extractant that is widely employed for the separation of rare earths due to its high selectivity and extractant capacity. ${ }^{16,57}$ Cyanex 923 is a solvating extractant that has been widely used for the separation of rare earths in nitrate media. ${ }^{16,57}$ Table 2 shows the distribution ratios of Nd and Dy when extracted from the DES using Cyanex 923 and D2EHPA.

D2EHPA allowed the obtention of higher distribution ratios than Cyanex 923 but the separation factors were similar, $\mathrm{SF}_{\mathrm{Dy} / \mathrm{Nd}}$ 
Table 2 Distribution ratios $D$ of neodymium and dysprosium from the eutectic mixture of choline chloride and lactic acid (molar ratio $1: 2)^{a}$

\begin{tabular}{llr}
\hline & \multicolumn{1}{c}{$D_{\mathrm{Nd}}$} & \multicolumn{1}{c}{$D_{\mathrm{Dy}}$} \\
\hline Cyanex 923 (0.9 M in toluene) & $0.14 \pm 0.07$ & $1.79 \pm 0.10$ \\
D2EHPA (0.9 M in toluene) & $2.23 \pm 0.09$ & $28.85 \pm 2.53$
\end{tabular}

${ }^{a}$ Shaking speed: $2000 \mathrm{rpm}$, equilibration time: $60 \mathrm{~min}, 25^{\circ} \mathrm{C}$.

$=12.93$ and 12.79 for D2EHPA and Cyanex 923 respectively. Since solvent extraction processes must not be analyzed only in terms of their distribution ratios, but also considering the stripping procedure and their feasibility to be scaled up, it was decided to study both systems to compare them and choose the most adequate one. The kinetics of extraction of both systems was studied at $25{ }^{\circ} \mathrm{C}$ and in both cases, the equilibrium is reached somewhere in between 5 and $10 \mathrm{~min}$. Taking this into account, 15 min was chosen as the optimal time to carry out further experiments.

The next parameter investigated was the effect of the concentration of extractant in the less polar phase. In both cases the distribution ratios for both rare-earth metals increase as the concentration of extractant increases (Fig. 4 and 5). Concentrations of extractant higher than $0.9 \mathrm{M}$ resulted in higher distribution ratios but also in a loss of the selectivity.

In general, the extraction of rare earths by organophosphorous acids, such as D2EHPA, can be expressed as follows, ${ }^{\mathbf{1 6}}$

$$
\mathrm{RE}^{3+}+\overline{m(\mathrm{HA})_{2}} \rightleftharpoons \overline{\mathrm{REA}_{3}(\mathrm{HA})_{2 m-3}}+3 \mathrm{H}^{+}
$$

where $(\mathrm{HA})_{2}$ represents the dimer of D2EHPA, and RE denotes a rare earth element. The equilibrium constant $K$ of the reaction can be written as follows,

$$
K=\frac{\overline{\left[\mathrm{REA}_{3}(\mathrm{HA})_{2 m-3}\right]}\left[\mathrm{H}^{+}\right]^{3}}{\left[\mathrm{RE}^{3+}\right] \overline{\left[(\mathrm{HA})_{2}\right]^{m}}}=\frac{D\left[H^{+}\right]^{3}}{\overline{\left[(\mathrm{HA})_{2}\right]^{m}}}
$$

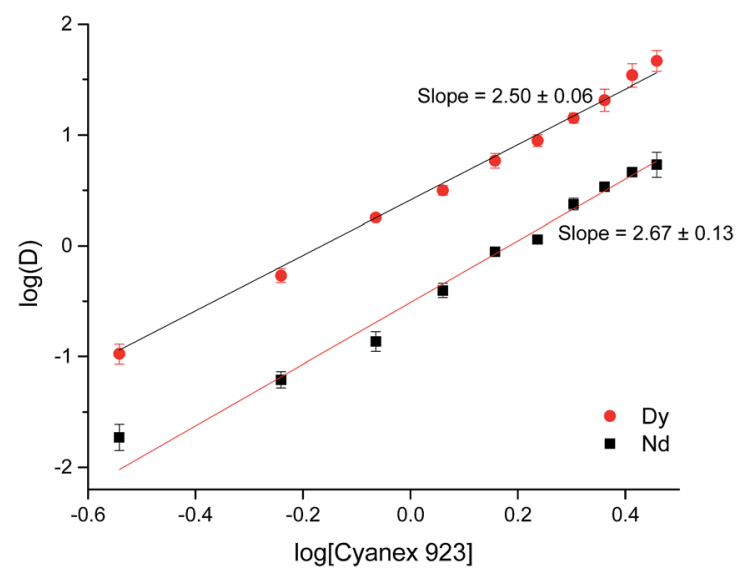

Fig. 4 Effect of the concentration of Cyanex 923 diluted in toluene on the separation of neodymium and dysprosium in the DES choline chloride: lactic acid (molar ratio 1:2). Equilibration time: 15 min. Shaking speed: $2000 \mathrm{rpm}$ at $25^{\circ} \mathrm{C}$. Concentration in the aqueous phase was $16 \mathrm{mM} \mathrm{Nd}$ and $0.7 \mathrm{mM}$ Dy.

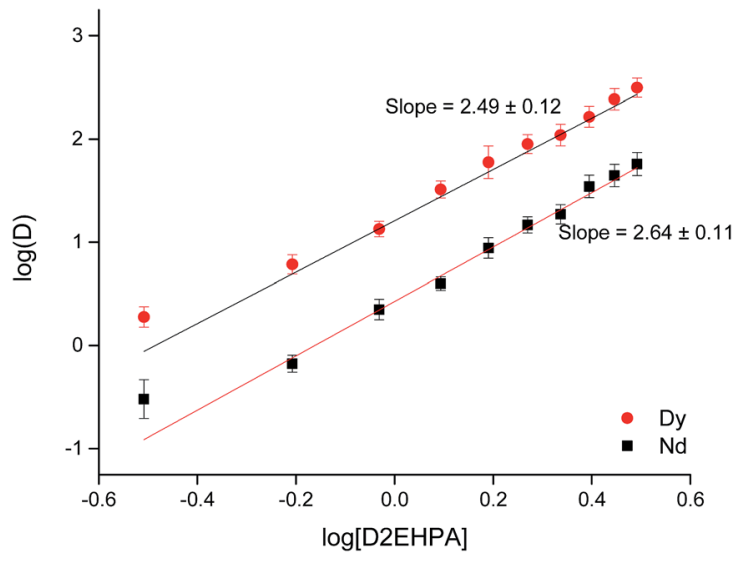

Fig. 5 Effect of the concentration of D2EHPA diluted in toluene on the separation of neodymium and dysprosium in the DES choline chloride : lactic acid (molar ratio $1: 2$ ). Equilibration time: $15 \mathrm{~min}$. Shaking speed: $2000 \mathrm{rpm}$ at $25^{\circ} \mathrm{C}$. Concentration in the aqueous phase was $16 \mathrm{mM} \mathrm{Nd}$ and $0.7 \mathrm{mM}$ Dy.

Taking logarithm on both sides, the following equation is obtained,

$$
\log D=-3 \log \left[\mathrm{H}^{+}\right]+m \log \left[(\mathrm{HA})_{2}\right]+\log K(\mathrm{HA})_{2}
$$

when the concentration of $\left[\mathrm{H}^{+}\right]$is constant, the plot of $\log D$ against $\log \left[(\mathrm{HA})_{2}\right]$ should give a straight line with a slope of the value of $m$.

On the other hand, the extraction reaction using Cyanex 923 can be expressed by eqn (15),

$$
\mathrm{RE}^{3+}+3 \mathrm{Cl}^{-}+\overline{m \mathrm{~B}} \rightleftharpoons \overline{\mathrm{RECl}_{3} \cdot m \mathrm{~B}}
$$

The equilibrium constant can be written as,

$$
K_{\mathrm{B}}=\frac{\overline{\left[\mathrm{RECl}_{3} \cdot m \mathrm{~B}\right]}}{\left[\mathrm{RE}^{3+}\right]\left[\mathrm{Cl}^{-}\right]^{3} \overline{[\mathrm{B}]^{m}}}=\frac{D}{\left[\mathrm{Cl}^{-}\right]^{3} \overline{[\mathrm{B}]^{m}}}
$$

where B represents Cyanex 923. The logarithm of the distribution ratio depends only on the concentrations of Cyanex 923 and $\mathrm{Cl}^{-}$, as shown in eqn (17),

$$
\log D=3 \log \left[\mathrm{Cl}^{-}\right]+m \log [\mathrm{B}]+\log K_{\mathrm{B}}
$$

when the chloride concentration is constant, the plot of $\log D$ against $\log [\mathrm{B}]$ should give a slope of the value of $m$.

From Fig. 4 and 5 it can be observed that the slopes had values close to 2.5 for both Nd and Dy extracted from DES with Cyanex 923 or D2EHPA. The slopes are non-integer values, indicating that more than one type of complex is involved in the extraction or that there is a molecular aggregation of the extractants in the solvent. These slopes are in concordance with what has been published previously by other authors. ${ }^{\mathbf{1 6 , 5 8 - 6 2}}$ Cyanex 923 has been widely used in the extraction of rare earths from nitrate media. ${ }^{62-64}$ In general, solvating extractants have been mostly used when extracting from nitrate media because they offer higher distribution ratios and separation factors than from chloride media. $^{65}$ Therefore, the use of solvating 
extractants to extract rare earths from chloride media has been barely reported..$^{62,65-67}$ When using Cyanex 923 to extract rare earths from chloride media, the distribution ratios for heavy rare earths were higher than those for light rare earths, which is in agreement with what has been found in this work for the extraction of Nd and Dy from DES and also with other works on the extraction of REEs with Cyanex 923 from different aqueous feeds. ${ }^{60-62}$

Stripping. The percentage of stripping is defined in eqn (18).

$$
\% S=\frac{[\mathrm{M}]_{\mathrm{aq}}}{[\mathrm{M}]_{\mathrm{bs}}} \times 100
$$

where $[\mathrm{M}]_{\mathrm{aq}}$ corresponds to the concentration of metal ion in the more polar phase after stripping and phase separation and $[\mathrm{M}]_{\mathrm{bs}}$ is the concentration in the less polar phase before stripping.

The stripping of $\mathrm{Fe}$, Co and B from the less polar phase consisting of the ionic liquid [A336][SCN] diluted in toluene (0.9 $\mathrm{M})$ was studied. Diluted and concentrated acids were employed as well as $\mathrm{NaOH}$, EDTA and citric acid (Table 3).

The use of $\mathrm{NaOH}$ as stripping agent allowed precipitation stripping of Fe and Co. B was only back-extracted to the aqueous phase when using high concentrations of $\mathrm{NaOH}(8 \mathrm{M})$. It has been reported that at very high concentrations of $\mathrm{NaOH}$ or $\mathrm{KOH}$, B can be stripped by the formation of $\mathrm{Na}_{2} \mathrm{~B}_{4} \mathrm{O}_{7}$ and $\mathrm{K}_{2} \mathrm{~B}_{4} \mathrm{O}_{7}$ at high pH. ${ }^{68}$ One disadvantage of this method is the formation of the non-coarse precipitate of hydroxides of iron and cobalt that is difficult to filter, besides the fact that high concentrations of $\mathrm{NaOH}$ are required to precipitate all the metals. $\mathrm{HCl}$ was also tested but it was not a good stripping agent for $\mathrm{Fe}(\mathrm{III})$ and $\mathrm{Co}(\mathrm{II})$ due to the strong complexes formed between the thiocyanate ions and these metal ions. When $\mathrm{HCl}$ was used as stripping agent, Fe and Co were not back-extracted, however, B could easily be stripped since it is less strongly extracted. As expected, EDTA was a good complexing agent for stripping Fe and Co, but a poor one for B. Citric acid was not a better alternative than EDTA because the stability constants for the formation of the complexes are smaller with citric acid $\left(\log K_{\mathrm{Co}}=4.4\right.$ and $\log K_{\mathrm{Fe}}$ $=11.8)$ than with EDTA $\left(\log K_{\mathrm{Co}}=16.21\right.$ and $\left.\log K_{\mathrm{Fe}}=14.3\right){ }^{69,70}$ To achieve complete stripping, the solution can be treated with $6 \mathrm{M} \mathrm{HCl}$ to remove B, followed by a treatment with $1.2 \mathrm{M}$ EDTA to remove Fe and Co.

After the removal of Fe, Co and B, Dy can be separated from Nd by using either Cyanex 923 or D2EHPA diluted in toluene $(0.9 \mathrm{M})$ as previously discussed. Since $\mathrm{Nd}$ is one of the main components of the magnet, it is present in the leachate in higher concentrations (i.e. $0.016 \mathrm{M}$ ) than Dy (i.e. $0.001 \mathrm{M}$ ). Therefore, Nd is also co-extracted during the removal of Dy using the above mentioned extractants. To remove the $\mathrm{Nd}$ that is co-extracted with Dy to the less polar phase, a scrubbing procedure is necessary. $\mathrm{CaCl}_{2}$ at different concentrations was tested as scrubbing agent (Table 4).

From Table 4 it can be seen that no selectivity can be achieved at very low concentrations of $\mathrm{CaCl}_{2}$ since both $\mathrm{Nd}$ and Dy are stripped. However, selectivity can be achieved when working at higher concentrations of $\mathrm{CaCl}_{2}$ because the presence of chloride anions increases the distribution of heavy rare earths towards the less polar phase. When D2EHPA was used as extractant, this scrubbing step with $\mathrm{CaCl}_{2}$ could not be carried out since the metals are not easily stripped by water and the presence of high chloride concentrations favours their distribution in the less polar phase. Thus, $5.6 \mathrm{M} \mathrm{CaCl}_{2}$ was selected as scrubbing agent and was employed to purify the Dy-rich less polar phase obtained after running the mixer-settlers using 0.9 M Cyanex 923 in toluene. No co-extraction of Ca was observed when using Cyanex 923 as extractant. The stripping of Dy was evaluated using different stripping agents and the results are summarized in Table 5.

From Table 5, a clear difference in the stripping behaviour of the two systems is observed since the $D$ were lower for all the stripping agents that were used when stripping from the Cyanex 923 in comparison to stripping from the D2EHPA phase. This can be explained because of the high affinity of the acidic extractant D2EHPA for the rare earths. With this extractant very

Table 3 Distribution ratios $(D)$ obtained by the stripping of a metal loaded solution of [A336][SCN] in toluene $(0.9 \mathrm{M})$ with various aqueous solutions ${ }^{a}$

\begin{tabular}{|c|c|c|c|c|}
\hline Stripping agent & Concentration (M) & $D_{\mathrm{Fe}} \pm \mathrm{SD}(\% S)$ & $D_{\mathrm{B}} \pm \mathrm{SD}(\% S)$ & $D_{\mathrm{Co}} \pm \mathrm{SD}(\% S)$ \\
\hline \multirow[t]{3}{*}{$\mathrm{NaOH}$} & 8.0 & $0.66 \pm 0.02(60.3)$ & $2.20 \pm 0.13(31.2)$ & $0.47 \pm 0.01(68.2)$ \\
\hline & 2.0 & $1.18 \pm 0.04(45.8)$ & n.d. ${ }^{b}$ & $3.95 \pm 0.33(20.2)$ \\
\hline & 0.5 & $3.78 \pm 0.11(20.9)$ & n.d. ${ }^{b}$ & $>200$ \\
\hline \multirow[t]{2}{*}{$\mathrm{HCl}$} & 6.0 & $>200$ & $0.32 \pm 0.01(75.8)$ & $122 \pm 8(0.81)$ \\
\hline & 3.0 & $>200$ & $0.53 \pm 0.02(65.2)$ & $107 \pm 10(0.92)$ \\
\hline \multirow[t]{4}{*}{ EDTA } & 1.2 & $0.03 \pm 0.01(98.7)$ & n.d. ${ }^{b}$ & $0.03 \pm 0.01$ \\
\hline & 0.4 & $1.44 \pm 0.03(40.9)$ & n.d. ${ }^{b}$ & $1.35 \pm 0.03(42.5)$ \\
\hline & 0.1 & $2.52 \pm 0.12(28.4)$ & n.d. ${ }^{b}$ & $61.5 \pm 1.5(1.6)$ \\
\hline & 0.05 & $5.13 \pm 0.28(16.3)$ & n.d. ${ }^{b}$ & $>200$ \\
\hline Citric acid & 0.4 & $8.43 \pm 0.23(10.6)$ & n.d. ${ }^{b}$ & $29.3 \pm 3.7(3.3)$ \\
\hline
\end{tabular}

${ }^{a}$ Equilibration time $60 \mathrm{~min}, 25^{\circ} \mathrm{C}, 2000 \mathrm{rpm} .{ }^{b}$ Not detected (below detection limit). In the cases where $D$ are higher than 200 , the value of the $\%$ can be considered as very close to zero. 
Table 4 Effect of the $\mathrm{CaCl}_{2}$ concentration on the scrubbing of $\mathrm{Nd}$ and Dy from the less polar phase (0.9 M Cyanex 923 in toluene) ${ }^{a}$

\begin{tabular}{lll}
\hline $\mathrm{CaCl}_{2}(\mathrm{M})$ & $D_{\mathrm{Nd}} \pm \mathrm{SD}$ & $D_{\text {Dy }} \pm \mathrm{SD}$ \\
\hline 5.6 & $0.64 \pm 0.06$ & $>200$ \\
4.2 & $0.73 \pm 0.10$ & $57.8 \pm 3.8$ \\
2.8 & $1.05 \pm 0.07$ & $3.69 \pm 0.13$ \\
1.4 & $0.65 \pm 0.07$ & $0.38 \pm 0.06$ \\
0.7 & $0.45 \pm 0.12$ & $0.16 \pm 0.09$
\end{tabular}

${ }^{a} 25{ }^{\circ} \mathrm{C}, 2000 \mathrm{rpm}, 40 \mathrm{~min}$. Concentrations in the less polar phase: $0.003 \mathrm{M}$ for $\mathrm{Nd}$ and $0.002 \mathrm{M}$ for Dy (concentrations of the raffinate obtained from the mixer settler).

Table 5 Distribution ratios $(D)$ obtained by stripping a loaded solution of Cyanex 923 in toluene $(0.9 \mathrm{M})$ and D2EHPA in toluene $(0.9 \mathrm{M})^{a}$

\begin{tabular}{lll}
\hline & $\begin{array}{l}D_{\mathrm{Dy}} \text { from } \\
\text { Cyanex } 923 \text { in toluene } \\
0.9 \mathrm{M}(\% \mathrm{O})\end{array}$ & $\begin{array}{l}D_{\mathrm{Nd}} \text { from D2EHPA } \\
\text { in toluene } \\
0.9 \mathrm{M}(\% S)\end{array}$ \\
Stripping agent & $0.016 \pm 0.007(99.4)$ & $>200$ \\
Water & $0.012 \pm 0.010(99.6)$ & $0.31 \pm 0.09(75.9)$ \\
$0.5 \mathrm{M} \mathrm{HCl}$ & $0.019 \pm 0.009(99.0)$ & $>200$ \\
$0.1 \mathrm{M}$ citric acid & $0.24 \pm 0.03(81.0)$ & $>200$
\end{tabular}

${ }^{a}$ Equilibration time: $40 \mathrm{~min}, 25^{\circ} \mathrm{C}, 2000 \mathrm{rpm}$. Concentration of Dy in the less polar phase after the scrubbing: $0.002 \mathrm{M}$. In the cases where $D$ are higher than 200 , the value of the $\% S$ can be considered as very close to zero.

high distribution ratios can be achieved for heavy rare earths, but the stripping is difficult. Because of the easiness of scrubbing and stripping when Cyanex 923 is used, Cyanex 923 was chosen as optimal extractant for the separation of Dy from $\mathrm{Nd}$ and water was selected as stripping agent. Once Dy was removed from the DES phase (i.e. by counter-current extraction), it was necessary to find a way to strip Nd from the DES. With this aim, precipitation stripping with oxalic acid was explored. Different amounts of oxalic acid were contacted with the DES and then stirred at $25^{\circ} \mathrm{C}$ and $2000 \mathrm{rpm}$ during $25 \mathrm{~min}$. After this time, the precipitate was removed and the aqueous phase quantified by ICP-OES. A stoichiometric amount of oxalic acid was needed to precipitate all Nd present in the DES, as stated in eqn (19). Using an excess of oxalic acid is not recommended since the deep eutectic solvent choline chloride: oxalic acid can be formed (Fig. S1†).

$$
2 \mathrm{Nd}^{3+}+3 \mathrm{H}_{2} \mathrm{C}_{2} \mathrm{O}_{4} \rightarrow \mathrm{Nd}_{2}\left(\mathrm{C}_{2} \mathrm{O}_{4}\right)_{3}+6 \mathrm{H}^{+}
$$

\section{Separation by mixer-settlers}

The feasibility of scaling up the extraction processes was tested using small mixer-settlers. Besides determining the extractant, the composition of the less polar phases, the contact time, the stripping agent and evaluating other parameters such as phase disengagement, the number of stages needed for the separation of Fe, B and Co from Nd and Dy was also determined. McCabe Thiele diagrams showing the loading of Fe, Co and $\mathrm{B}$ at different light phase : heavy phase ratios (LP:HP) from a solution containing all the metals (Fe, B, Co, Nd and Dy) were constructed. It was estimated that one stage was needed for $\mathrm{Fe}$ and Co extraction, approximately three for $\mathrm{B}$ extraction when using an LP : HP ratio of $1: 1$. At a LP : HP ratio of $2: 1$ one stage is needed for Fe and Co and two for B (Fig. S2-S4†). In total, three stages would be necessary for the complete extraction of Fe, Co and B from Nd and Dy. However two more stages were put as precaution in case more stages were needed due to the relative high viscosity of the more polar phase.

The extraction behaviour of Fe, Co and B in the mixer-settler is presented in Fig. 6. Every hour a sample was taken from each extraction chamber throughout the day and analysed by
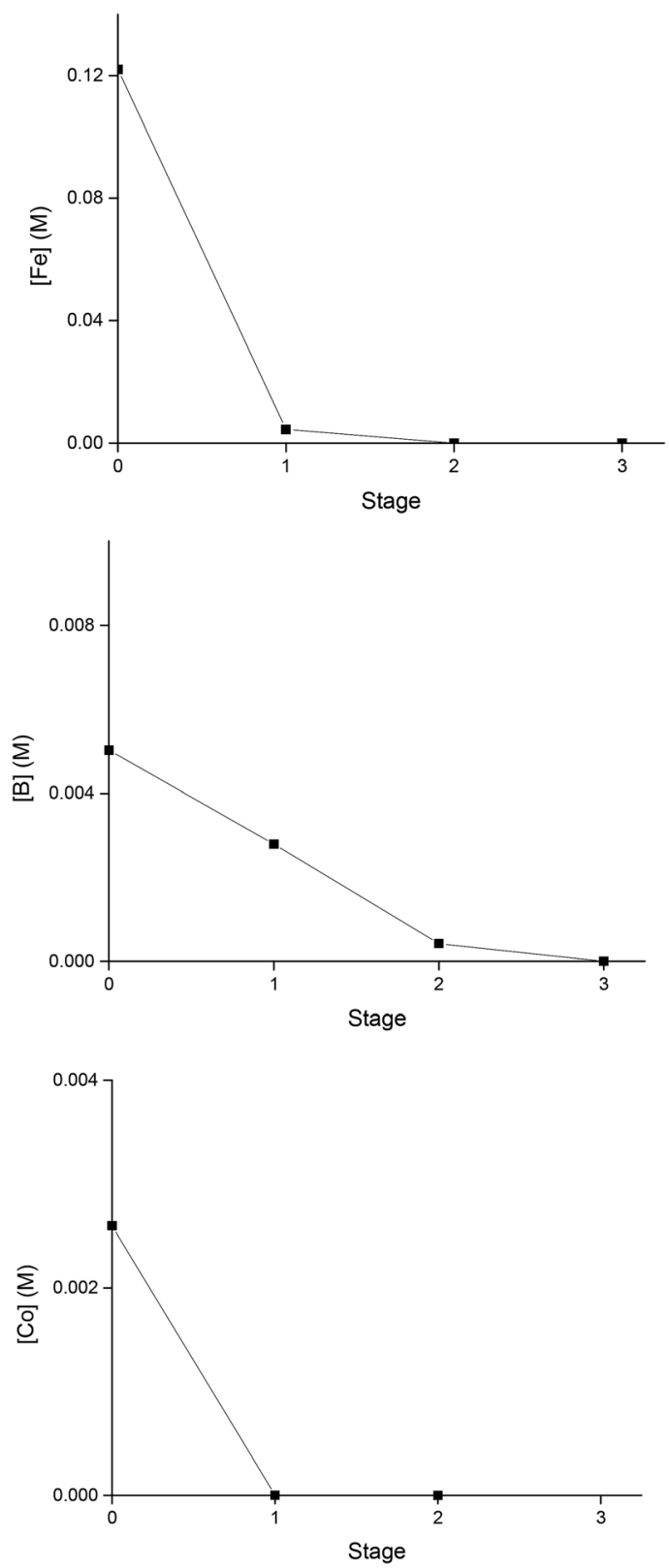

Fig. 6 Extraction behaviour of iron (top), boron (center) and cobalt (bottom) from the DES choline chloride : lactic acid (molar ratio $1: 2$ ). The extraction was carried out with [A336][SCN], (0.9 M in toluene). The LP : HP phase ratio was $1: 1$. 
ICP-OES. The extraction system showed a good stability over time, with minor variations in metal concentrations between the samples. In the first stage, the concentration of Fe and Co in the DES decreased considerably. On the other hand, B required three stages to be completely recovered from the DES. During the whole time of operation, no precipitate or third phase formation was observed. The experimental data obtained with the mixer-settlers showed that the fourth and fifth stages were not needed since at those stages Fe, Co and B were not detected in the more polar phase.

After the removal of $\mathrm{Fe}$, Co and B, Nd and Dy remained in the DES solution. As it was previously discussed, the extractant, its concentration, the kinetics and the stripping agent were evaluated. Cyanex 923 (0.9 M in toluene) was selected as the less polar phase to carry out the separation of Dy from $\mathrm{Nd}$ in the mixer settlers since good separation factors were achieved, the stripping could be carried out efficiently using water and the system presented fast and good phase disengagement (important when running mixer settlers). Fig. S5 in the ESI $\dagger$ shows the extraction isotherm of Dy at different LP : HP ratios from an eutectic mixture of choline chloride and lactic acid (molar ratio $1: 2$ ) containing only $\mathrm{Nd}$ and $\mathrm{Dy}$. It was estimated that approximately three stages were needed when working at an LP : HP phase ratio of $1: 1$ and two stages when using an LP : HP phase ratio of $2: 1$. An LP : HP phase ratio of $2: 1$ was chosen since it allows the less number of stages. No formation of a third phase, precipitate or gel was observed at any point of the separation study. One extra stage was added to the system in order to assure complete extraction of the Dy in the case that two stages were not enough when testing the separation system in the mixer settlers.

The extraction behaviour of Dy is presented in Fig. 7. Every hour a sample was taken from each extraction chamber throughout the day and analysed with ICP-OES. The extraction showed good stability over time, with minor variations in metal concentrations between the samples. In the first stage, the concentration of Dy in the more polar phase was decreased by almost the half and on the second stage it was close to $0 \mathrm{M}$. No

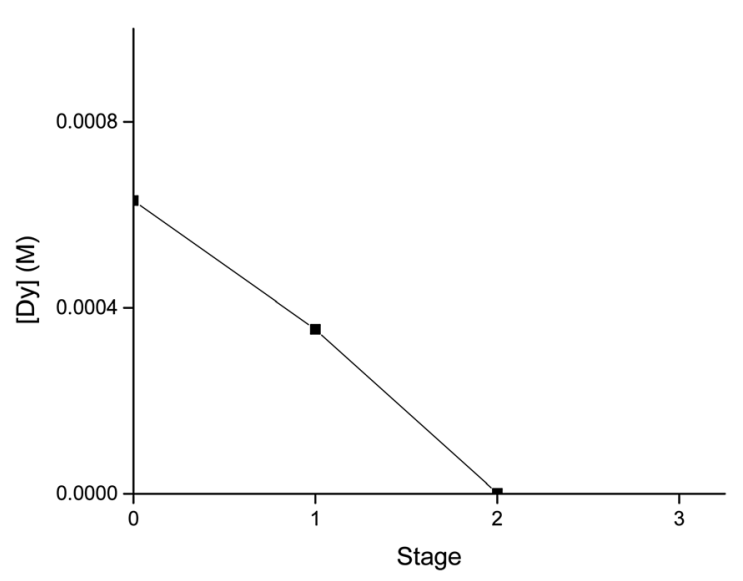

Fig. 7 Extraction behaviour of Dy from the deep-eutectic solvent choline chloride : lactic acid (1:2). The extraction was carried out with Cyanex 923 (0.9 M in toluene). The LP : HP phase ratio was $2: 1$.
Dy was detected on the third stage. The experimental data with the mixer settlers showed that two stages, when working at an LP : HP phase ratio of $2: 1$ were needed to successfully separate Dy from the Nd.

After extraction, part of the raffinate containing mainly $\mathrm{Nd}$ was contacted with a stoichiometric amount of oxalic acid and stirred at $25{ }^{\circ} \mathrm{C}$ during $30 \mathrm{~min}$. The light pink precipitate that was obtained was filtered, washed with water and ethanol and then calcined at $950{ }^{\circ} \mathrm{C}$ during 3 hours. The blue powder that was obtained was analyzed by XRD and corresponded to $\mathrm{Nd}_{2} \mathrm{O}_{3} \cdot{ }^{71}$ The dissolution of this powder in concentrated $\mathrm{HCl}$ and its quantification with ICP-OES indicated a purity of $99.87 \%$ and $0.13 \%$ of Dy. The less polar phase obtained from the mixer settler, rich in Dy and containing Nd was scrubbed manually in a separatory funnel, 5 times, with $6 \mathrm{M} \mathrm{CaCl}_{2}$ and then the Dy was stripped with water, precipitated with oxalic acid and calcined at $950{ }^{\circ} \mathrm{C}$. The obtained white powder was analyzed by XRD which indicated that it corresponded to $\mathrm{Dy}_{2} \mathrm{O}_{3},{ }^{72}$ the purity was determined by ICP and it corresponded to $99.94 \%$ Dy and $0.06 \% \mathrm{Nd}$ as impurity.

\section{Recycling of the less polar phases}

After the removal of Fe, B and Co from the feed solution with the ionic liquid [A336] $\mathrm{SCN}$ ] (0.9 $\mathrm{M}$ in toluene) and the stripping of these elements using $6 \mathrm{M} \mathrm{HCl}$ and 1.5 M EDTA pH 5.6, the less polar phase, without any further treatment, was put in contact with a fresh DES mixture containing Fe, B, Co, Nd and Dy. In a similar experiment, the less polar phase was equilibrated with KSCN before its reuse in a new extraction. Results are presented in Table 6.

Table 6 shows how after the stripping of Fe, B and Co with $\mathrm{HCl}$ and EDTA, the less polar phase can be re-used for the extraction of these metals. The percentages of extraction for $\mathrm{Fe}$ and Co are comparable to the ones obtained when carrying out the extraction for the first time (Table 1). However, in the case of $\mathrm{B}$, higher percentages extraction were obtained and they are comparable to the ones obtained when [A336][Cl] was used as extractant. When the less polar phase is equilibrated with $2.5 \mathrm{M}$ KSCN before its re-use, the percentages extraction that are obtained are similar to those observed when working with [A336] [SCN]. This could indicate that there is an anionic exchange mechanism when using [A336][SCN], therefore, after extraction, the less polar phase is richer in chloride ions, which explains why the higher percentages of extraction for boron when the less polar phase is reused without equilibration with KSCN. In fact, the analysis of the less polar phase with TXRF after extraction indicated the presence of chloride peaks.

Table 6 Re-use of the less polar phase (0.9 M [A336][SCN] in toluene) for the extraction of $\mathrm{Fe}, \mathrm{B}$ and $\mathrm{Co}^{a}$

\begin{tabular}{lccc}
\hline Less polar phase & $D_{\mathrm{Fe}} \pm \mathrm{SD}$ & $D_{\mathrm{B}} \pm \mathrm{SD}$ & $D_{\mathrm{Co}} \pm \mathrm{SD}$ \\
\hline Without treatment & $30.3 \pm 1.4$ & $2.6 \pm 0.2$ & $65.7 \pm 2.4$ \\
Equilibrated with $[\mathrm{SCN}]^{-}$ & $52.9 \pm 4.9$ & $0.84 \pm 0.07$ & $199 \pm 8$
\end{tabular}

${ }^{a} 25$ min equilibration time, $2000 \mathrm{rpm}, 25{ }^{\circ} \mathrm{C}$. 
After stripping with water, the less polar phase (Cyanex 923 diluted in toluene $0.9 \mathrm{M}$ ), was re-used to extract Dy from the mixture of Nd and Dy in the DES of choline chloride : lactic acid (molar ratio $1: 2$ ) and no significant deviations from the results obtained when using the extractant for the first time were encountered.

\section{Comparison with conventional systems}

The developed system was compared to the traditional liquidliquid extraction systems composed by an aqueous phase and an organic phase. Since the concentration of chloride anions in the DES is close to $3 \mathrm{M}$, it was decided to carry out the experiments with an aqueous phase containing $1.5 \mathrm{M} \mathrm{CaCl}_{2}$ to have a concentration of chloride anions close to the one present in the DES, a concentration of $5 \mathrm{M} \mathrm{CaCl}_{2}$ in the aqueous phase was also tested for comparison (Table 7).

From Table 7 it can be seen how higher $D$ for Fe and Co are obtained when extracting from DESs. Moreover, the extraction of B is not possible from the aqueous system. The extraction of metal ions from the aqueous system can be improved by addition of $\mathrm{CaCl}_{2}$ but by doing this, the selectivity is lost since Dy and Nd are co-extracted. The use of a DES as the more polar phase was also beneficial for the separation of $\mathrm{Nd}$ and Dy in comparison to conventional aqueous systems (Table 8). When extracting $\mathrm{Nd}$ and Dy at these concentrations from aqueous systems, low $D$ and SF are obtained. When extracting from DESs, better separation factors are obtained. This can be due to the presence of lactic acid in the more polar phase. It has been reported how a complexing agent that can form complexes with rare-earth cations (with different equilibrium constants) can significantly increase the possibility of selectively separate the different rare earth cations. The complexation of rare-earth cations with enhances the sorption performance and improves the selectivity. ${ }^{73-75}$ This highlights the importance of these new systems and the importance of studying and improving them. Fig. 8 shows the flow sheet for a process to separate $\mathrm{Fe}, \mathrm{B}$ and Co from Nd and Dy in a DES and afterwards to separate Dy from Nd using [A336][SCN] (0.9 M in toluene) and Cyanex 923 (0.9 M in toluene), respectively.

\section{EXAFS}

Understanding of the mechanism of extraction is crucial in every single extraction process. When it is understood how the extraction occurs, the process can be optimized and redesigned in order to create better systems in terms of efficiency and
Table 8 Comparison between the proposed system and a traditional liquid-liquid extraction system with an aqueous solution for the removal of Dy using 0.9 M Cyanex 923 in toluene ${ }^{a}$

\begin{tabular}{lll}
\hline More polar phase & $D_{\mathrm{Nd}} \pm \mathrm{SD}$ & $D_{\mathrm{Dy}} \pm \mathrm{SD}$ \\
\hline ChCl : lactic acid (molar ratio $1: 2)$ & $0.17 \pm 0.09$ & $1.89 \pm 1.2$ \\
Aqueous phase (without $\left.\mathrm{CaCl}_{2}\right)$ & $0.10 \pm 0.02$ & $0.23 \pm 0.06$ \\
Aqueous phase $\left(\mathrm{CaCl}_{2} 1.5[\mathrm{M}]\right)$ & $0.29 \pm 0.06$ & $0.55 \pm 0.12$ \\
Aqueous phase $\left(\mathrm{CaCl}_{2} 5[\mathrm{M}]\right)$ & $0.45 \pm 0.05$ & $0.77 \pm 0.13$
\end{tabular}

${ }^{a}$ Equilibration time: $60 \mathrm{~min}, 2000 \mathrm{rpm}, 25^{\circ} \mathrm{C}$.

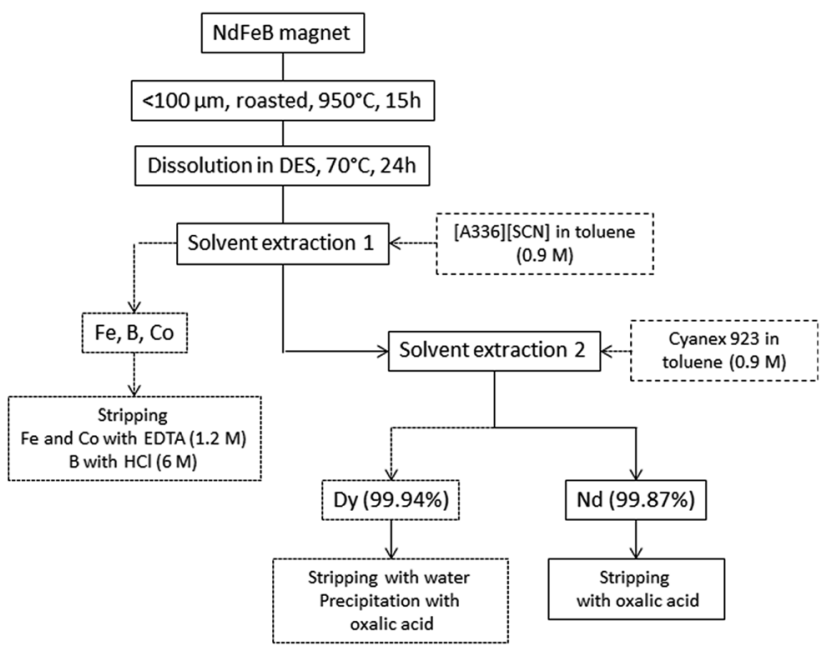

Fig. 8 Flow sheet for a process consisting of dissolution of a NdFeB magnet in the DES choline chloride: lactic acid (molar ratio $1: 2$ ), followed by the removal of Fe, B and Co with $0.9 \mathrm{M}$ [A336][SCN] in toluene and afterwards, the separation of $\mathrm{Nd}$ and Dy with Cyanex 923 $0.9 \mathrm{M}$ in toluene.

consumption of chemicals. The extraction of transition metals and rare earths using conventional extractants from aqueous systems is described extensively in the literature. ${ }^{14,16,57}$ However, the mechanism of extraction from DESs has not been studied yet. The mechanism of extraction of Fe and Co with [A336][SCN] $0.9 \mathrm{M}$ in toluene was studied from the DES phase and compared against the extraction of the same metals from aqueous solutions.

A fit of the first coordination shell of iron extracted from the aqueous to the [A336][SCN] phase showed 6 nitrogen atoms. Therefore, a model containing 6 coordinating thiocyanate

Table 7 Comparison between the proposed system and a traditional liquid-liquid extraction system from an aqueous solution for the removal of $\mathrm{Fe}, \mathrm{B}$ and Co using 0.9 M [A336] [SCN] in toluene ${ }^{a}$

\begin{tabular}{|c|c|c|c|c|c|}
\hline More polar phase & $D_{\mathrm{Fe}} \pm \mathrm{SD}$ & $D_{\mathrm{B}} \pm \mathrm{SD}$ & $D_{\mathrm{Co}} \pm \mathrm{SD}$ & $D_{\mathrm{Nd}} \pm \mathrm{SD}$ & $D_{\text {Dy }} \pm \mathrm{SD}$ \\
\hline $\mathrm{ChCl}$ : lactic acid (molar ratio $1: 2$ ) & $44.5 \pm 2.6$ & $0.78 \pm 0.10$ & $193 \pm 2$ & $0.029 \pm 0.007$ & $0.025 \pm 0.008$ \\
\hline Aqueous phase (without $\mathrm{CaCl}_{2}$ ) & $5.7 \pm 0.3$ & n.d. ${ }^{b}$ & $10.0 \pm 1.4$ & n.d. ${ }^{b}$ & $0.080 \pm 0.009$ \\
\hline Aqueous phase $\left(\mathrm{CaCl}_{2} 5[\mathrm{M}]\right)$ & $49.6 \pm 1.5$ & $0.09 \pm 0.03$ & $72 \pm 1$ & $0.31 \pm 0.08$ & $0.45 \pm 0.07$ \\
\hline
\end{tabular}

${ }^{a}$ Equilibration time: $60 \mathrm{~min}, 2000 \mathrm{rpm}, 25^{\circ} \mathrm{C} .{ }^{b}$ n.d. $=$ not detected (below limit of detection). 
anions was used to fit the experimental data. A model including a linear $\mathrm{Fe}-\mathrm{N}-\mathrm{C}$ bond showed bad fits. In case of a non-linear $\mathrm{Fe}-\mathrm{N}-\mathrm{C}$ bond, four-leg scattering paths can be excluded if the bond angle is not close to $180^{\circ}$. A model including three two-leg scattering paths ( $\mathrm{Fe}-\mathrm{N}, \mathrm{Fe}-\mathrm{C}$ and $\mathrm{Fe}-\mathrm{S})$ and three three-leg scattering paths resulted in a good fit of the data. The degeneracy of the different paths were constrained but $S_{0}$ was allowed to vary resulting in a value of 0.95 . The distances to $\mathrm{N}, \mathrm{C}$ and $\mathrm{S}$ also proof the non-linearity of the $\mathrm{Fe}-\mathrm{N}-\mathrm{C}$ bond as the total sum of the bond lengths in $\mathrm{Fe}-\mathrm{N}-\mathrm{C}-\mathrm{S}$ is around $5 \AA$ and the fact that the three leg scattering paths to carbon and sulphur are significantly larger in distance than the two leg scattering paths to carbon and sulphur, respectively (Table S2, Fig. S6 and S7†).

The edge structure of the iron(III) complex extracted from the DES looked very similar to the edge structure previously observed for $\left[\mathrm{FeCl}_{4}\right]^{-}$complexes (Fig. S8 $\dagger$ ). ${ }^{76,77} \mathrm{~A}$ fit of the EXAFS region, including only $\mathrm{Fe}-\mathrm{Cl}$ single scattering paths resulted in a fit degeneracy of 3.4, a bond distance of $2.208 \AA$ and a Debye Waller factor of $0.004 \AA^{2}$. A slightly better fit was obtained when including also one $\mathrm{Fe}-\mathrm{O}$ path. However, this is contradictory to the rest of the Fourier transform as coordinating oxygen atoms can only come from lactic acid or choline. This suggests that there should be contributions to the FT at slightly higher $R$ values as well, which is not the case. Therefore, it can be concluded that iron extracts as a $\left[\mathrm{FeCl}_{4}\right]^{-}$complex to the less polar phase (Fig. 9 and 10).

Fitting of the first shell of the Co complex in the [A336][SCN] phase, as extracted from an aqueous solution, showed the presence of four nitrogen atoms. Therefore, a model consisting of four thiocyanate ligands was used to fit the experimental data. Three single scattering paths and three three-leg scattering paths were included, and of which the degeneracy was constrained. The amplitude reduction factor $S_{0}$ was set to 0.95 . Similarly to the $\left[\mathrm{Fe}(\mathrm{SCN})_{6}\right]^{3-}$ complex in $[\mathrm{A} 336][\mathrm{SCN}]$, the threeleg scattering paths $\mathrm{Co}-\mathrm{C}-\mathrm{N}, \mathrm{Co}-\mathrm{S}-\mathrm{C}$ and $\mathrm{Co}-\mathrm{S}-\mathrm{N}$ are larger than the distances between $\mathrm{Co}$ and $\mathrm{N}, \mathrm{C}$ and $\mathrm{Co}$, which indicates the non-linearity between the $\mathrm{Co}-\mathrm{N}-\mathrm{C}$ angle and the $\mathrm{N}-\mathrm{C}-\mathrm{S}$ angle (Table S3†).

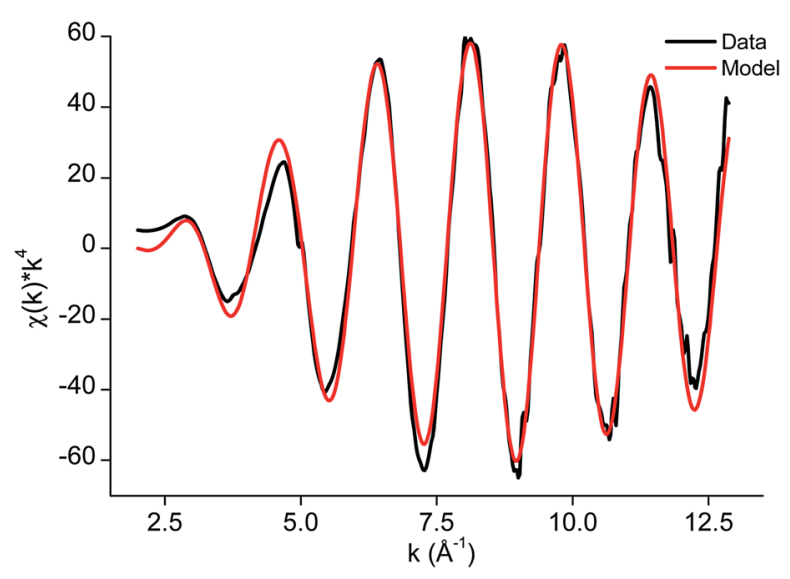

Fig. 9 EXAFS function $\chi(k) \times k^{4}$ and model of the $\left[\mathrm{FeCl}_{4}\right]^{-}$complex in [A336] [SCN] diluted in toluene $0.9 \mathrm{M}$, as extracted from the DES.

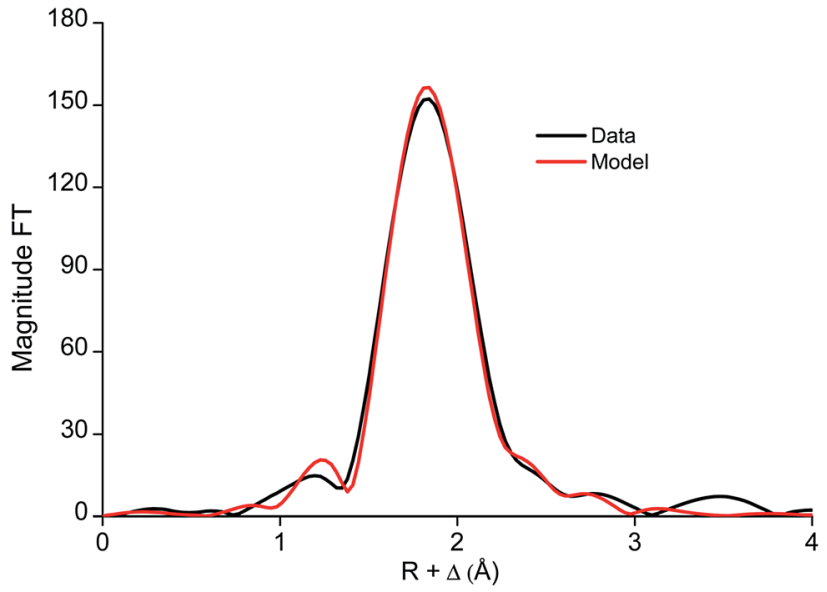

Fig. 10 Fourier transform and model of the $\left[\mathrm{FeCl}_{4}\right]^{-}$complex in [A336][SCN] diluted in toluene (0.9 M), as extracted from DES.

The EXAFS function of the Co complex extraction from the DES and from $5 \mathrm{M} \mathrm{CaCl}_{2}$ was very similar to the EXAFS function of Co extracted from an aqueous solution, which indicates that the $\left[\mathrm{Co}(\mathrm{SCN})_{4}\right]^{2-}$ complex is formed in both cases (Fig. S9†). This result is in contrast to the extraction of iron, where $\left[\mathrm{Fe}(\mathrm{SCN})_{6}\right]^{3-}$ complex is formed when extraction occurred from an aqueous solution, while a $\left[\mathrm{FeCl}_{4}\right]^{-}$complex is formed when extracted from DES (Fig. 11 and 12).

Furthermore, samples of the organic and the DES phase after extraction of Fe were taken and analyzed by ${ }^{1} \mathrm{H}$ NMR. Components of the DES were not detected in the less polar phase nor the Aliquat 336 cation was detected in the DES. The latter results in addition with the ones obtained by EXAFS, suggest that the mechanism of extraction of Fe from the DES choline chloride : lactic acid $(1: 2)$ corresponds to an anionic exchange (eqn (20)).

$$
\mathrm{Fe}^{3+}+4 \mathrm{Cl}^{-}+\overline{\overline{[\mathrm{A} 336][\mathrm{SCN}]}} \rightarrow \overline{\left[\mathrm{FeCl}_{4}\right][\mathrm{A} 336]}+\mathrm{SCN}^{-}
$$

This means that part of the thiocyanate anions are being exchanged by chloride anions from the DES phase and thus, the

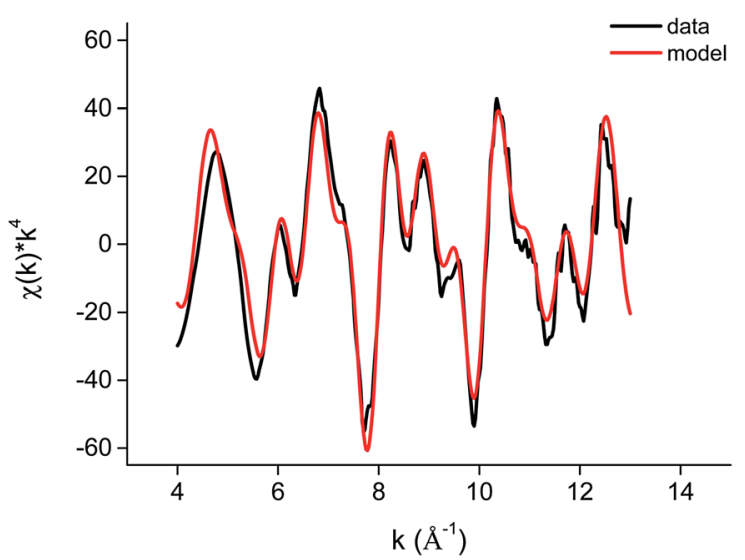

Fig. 11 EXAFS function $\chi(k) \times k^{4}$ and model of the $\left[\mathrm{Co}(\mathrm{SCN})_{4}\right]^{2-}$ complex. 


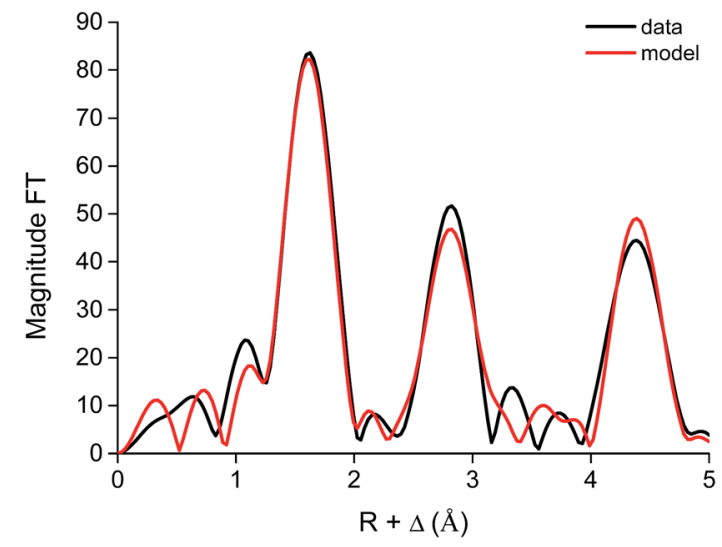

Fig. 12 Fourier transform and model of the $\left[\mathrm{Co}(\mathrm{SCN})_{4}\right]^{2-}$ complex in the ionic liquid [A336][SCN], as extracted from aqueous solution.

ionic liquid in the less polar phase is being degraded. This issue can be solved by contacting the less polar phase with $[\mathrm{SCN}]^{-}$ and regenerating the ionic liquid after extraction (Table 6).

\section{Conclusions}

For the first time a DES composed of choline chloride and lactic acid (molar ratio 1:2) was successfully employed for the complete dissolution of $\mathrm{NdFeB}$ magnets. Fe, Co and B were removed from this leachate using the ionic liquid [A336][SCN] as extractant diluted in toluene $(0.9 \mathrm{M})$. Cyanex 923 diluted in toluene $(0.9 \mathrm{M})$ was a better extractant for the separation of Dy from Nd than D2EHPA diluted in toluene, since it allowed easier scrubbing and stripping. As demonstrated by EXAFS measurements, the extraction mechanism from DESs is different from those from aqueous solutions, thus different distribution ratios and separation ratios were achieved. As a result, the use of DESs allowed higher selectivity for the removal of $\mathrm{Fe}$, Co and B from $\mathrm{Nd}$ and Dy and also for the separation of Dy from $\mathrm{Nd}$ in comparison with conventional liquid-liquid extraction systems. The feasibility of scaling up the proposed process was further confirmed by its implementation in a mixer-settler setup. It was found that the studied DES can be used at room temperature without any issue related to high viscosity, poor phase disengagement or third-phase formation. The metals were stripped by $\mathrm{HCl}$ and EDTA (for Fe, B and Co) and water (for Dy) from the less polar phase and a stoichiometric amount of oxalic acid for the removal of $\mathrm{Nd}$ from the DES. $\mathrm{Nd}_{2} \mathrm{O}_{3}$ and $\mathrm{Dy}_{2} \mathrm{O}_{3}$ were recovered with purities of $99.87 \%$ and $99.94 \%$, respectively.

\section{Acknowledgements}

The research leading to these results has received funding from the European Community's Seventh Framework Programme ([FP7/2007-2013]) under grant agreement no. 607411 (MC-ITN EREAN: European Rare Earth Magnet Recycling Network). This publication reflects only the author's view, exempting the Community from any liability. Project website: http:// www.erean.eu. Mehmet Ali Recai Önal (KU Leuven) is acknowledged for milling the magnets. The authors thank Stefan Möwius (BEC Gesellschaft für Produktmanagement $\mathrm{GmbH}$ ) and Žiga Erman (Magneti Ljubljana) for providing the NdFeB magnet samples, the FWO for the postdoctoral fellowship of TVDH and the VLAIO for the PhD scholarship to BO.

\section{References}

1 J. H. Rademaker, R. Kleijn and Y. Yang, Environ. Sci. Technol., 2013, 47, 10129-10136.

2 K. Binnemans, P. T. Jones, B. Blanpain, T. Van Gerven, Y. Yang, A. Walton and M. Buchert, J. Cleaner Prod., 2013, 51, 1-22.

3 Y. Yang, A. Walton, R. Sheridan, K. Güth, R. Gauß, O. Gutfleisch, M. Buchert, B.-M. Steenari, T. Van Gerven, P. T. Jones and K. Binnemans, J. Sustain. Metall., 2017, 3, 122-149.

4 R. Sasai and N. Shimamura, J. Asian. Cer. Soc., 2016, 4, 155158.

5 O. Takeda, T. H. Okabe and Y. Umetsu, J. Alloys Compd., 2006, 408-412, 387-390.

6 A. Walton, H. Yi, N. A. Rowson, J. D. Speight, V. S. J. Mann, R. S. Sheridan, A. Bradshaw, I. R. Harris and A. J. Williams, J. Cleaner Prod., 2015, 104, 236-241.

7 M. Zakotnik, I. R. Harris and A. J. Williams, J. Alloys Compd., 2008, 450, 525-531.

8 M. Zakotnik, I. R. Harris and A. J. Williams, J. Alloys Compd., 2009, 469, 314-321.

9 X. Li, M. Yue, M. Zakotnik, W. Liu, D. Zhang and T. Zuo, J. Rare Earths, 2015, 33, 736-739.

10 D. Dupont and K. Binnemans, Green Chem., 2015, 17, 856868.

11 S. Riano and K. Binnemans, Green Chem., 2015, 17, 29312942.

12 T. Vander Hoogerstraete, S. Wellens, K. Verachtert and K. Binnemans, Green Chem., 2013, 15, 919-927.

13 D. Beltrami, G. Cote, H. Mokhtari, B. Courtaud, B. A. Moyer and A. Chagnes, Chem. Rev., 2014, 114, 12002-12023.

14 S. Nishihama, T. Hirai and I. Komasawa, Ind. Eng. Chem. Res., 2001, 40, 3085-3091.

15 P. J. Panak and A. Geist, Chem. Rev., 2013, 113, 1199-1236.

16 F. Xie, T. A. Zhang, D. Dreisinger and F. Doyle, Miner. Eng., 2014, 56, 10-28.

17 Z. Zhu, W. Zhang and C. Y. Cheng, Hydrometallurgy, 2011, 105, 304-313.

18 M. K. Jha, D. Gupta, J.-C. Lee, V. Kumar and J. Jeong, Hydrometallurgy, 2014, 142, 60-69.

19 V. S. Kislik, in Solvent Extraction, Elsevier, Amsterdam, 2012, ch. 1, pp. 3-67.

20 V. S. Kislik, in Solvent Extraction, Elsevier, Amsterdam, 2012, ch. 3, pp. 113-156.

21 M. A. R. Önal, C. R. Borra, M. Guo, B. Blanpain and T. Gerven, J. Sustain. Metall., 2015, 1, 199-215.

22 M. Al-Harahsheh and S. W. Kingman, Hydrometallurgy, 2004, 73, 189-203.

23 S. S. Konyratbekova, A. Baikonurova and A. Akcil, Miner. Process. Extr. Metall. Rev., 2015, 36, 198-212. 
24 M. Sahin, A. Akcil, C. Erust, S. Altynbek, C. S. Gahan and A. Tuncuk, Sep. Sci. Technol., 2015, 50, 2587-2595.

25 Y. Dong, X. Sun, Y. Wang and Y. Chai, Hydrometallurgy, 2015, 157, 256-260.

26 T. Vander Hoogerstraete, B. Onghena and K. Binnemans, J. Phys. Chem. Lett., 2013, 4, 1659-1663.

27 X. Sun, C.-L. Do-Thanh, H. Luo and S. Dai, Chem. Eng. J., 2014, 239, 392-398.

28 X. Sun, H. Luo and S. Dai, Talanta, 2012, 90, 132-137.

29 J. Wang, J. Zhao, D. Feng, X. Kang, Y. Sun, L. Zhao and H. Liang, J. Rare Earths, 2016, 34, 83-90.

30 H.-L. Yang, W. Wang, H.-M. Cui and J. Chen, Chin. J. Anal. Chem., 2011, 39, 1561-1566.

31 K. Larsson and K. Binnemans, Hydrometallurgy, 2015, 156, 206-214.

32 A. Rout and K. Binnemans, Dalton Trans., 2014, 43, 18621872.

33 A. P. Abbott, G. Capper, D. L. Davies, K. J. McKenzie and S. U. Obi, J. Chem. Eng. Data, 2006, 51, 1280-1282.

34 G. R. T. Jenkin, A. Z. M. Al-Bassam, R. C. Harris, A. P. Abbott, D. J. Smith, D. A. Holwell, R. J. Chapman and C. J. Stanley, Miner. Eng., 2016, 87, 18-24.

35 E. L. Smith, A. P. Abbott and K. S. Ryder, Chem. Rev., 2014, 114, 11060-11082.

36 M. R. S. Foreman, Cogent Chem., 2016, 2, 1139289.

37 A. P. Abbott, J. C. Barron, K. S. Ryder and D. Wilson, Chem.-Eur. J., 2007, 13, 6495-6501.

38 Q. Zhang, K. De Oliveira Vigier, S. Royer and F. Jerome, Chem. Soc. Rev., 2012, 41, 7108-7146.

39 A. P. Abbott, G. Capper, D. L. Davies, R. K. Rasheed and P. Shikotra, Inorg. Chem., 2005, 44, 6497-6499.

40 B. Sprecher, Y. Xiao, A. Walton, J. Speight, R. Harris, R. Kleijn, G. Visser and G. J. Kramer, Environ. Sci. Technol., 2014, 48, 3951-3958.

41 W. Yan, S. Yan, D. Yu, K. Li, H. Li, Y. Luo and H. Yang, J. Rare Earths, 2012, 30, 133-136.

42 P. C. Dent, J. Appl. Phys., 2012, 111, 07A721.

43 J. O. Liljenzin, G. Persson, I. Svantesson and S. Wingefors, in Transplutonium Elements-Production and Recovery, American Chemical Society, 1981, vol. 161, ch. 13, pp. 203221.

44 K. V. Klementev, Nucl. Instrum. Methods Phys. Res., Sect. A, 2000, 448, 299-301.

45 M. Newville, J. Synchrotron Radiat., 2001, 8, 96-100.

46 L. K. Jakobsson, G. Tranell and I.-H. Jung, Metall. Trans. B, 2017, 48, 60-72.

47 M. I. Saleh, M. F. Bari and B. Saad, Hydrometallurgy, 2002, 63, 75-84.

48 A. A. Mhaske and P. M. Dhadke, Hydrometallurgy, 2001, 61, 143-150.

49 G. A. Clark, R. M. Izatt and J. J. Christensen, Sep. Sci. Technol., 1983, 18, 1473-1482.

50 A. Cieszynska and M. Wisniewski, Sep. Purif. Technol., 2010, 73, 202-207.
51 J. Yang, T. Retegan and C. Ekberg, Hydrometallurgy, 2013, 137, 68-77.

52 Y. Jin, Y. Ma, Y. Weng, X. Jia and J. Li, J. Ind. Eng. Chem., 2014, 20, 3446-3452.

53 N. Panda, N. Devi and S. Mishra, J. Rare Earths, 2012, 30, 794-797.

54 S. M. Liu, H. H. Liu, Y. J. Huang and W. J. Yang, Trans. Nonferrous Met. Soc. China, 2015, 25, 329-334.

55 D. Prat, A. Wells, J. Hayler, H. Sneddon, C. R. McElroy, S. Abou-Shehada and P. J. Dunn, Green Chem., 2016, 18, 288-296.

56 R. Pizer and R. Selzer, Inorg. Chem., 1984, 23, 3023-3026.

57 M. K. Jha, A. Kumari, R. Panda, J. Rajesh Kumar, K. Yoo and J. Y. Lee, Hydrometallurgy, 2016, 165, 2-26.

58 K. Ohto, M. Yano, K. Inoue, T. Yamamoto, M. Goto, F. Nakashio, S. Shinkai and T. Nagasaki, Anal. Sci., 1995, 11, 893-902.

59 D. Zheng, N. B. Gray and G. W. Stevens, Solvent Extr. Ion Exch., 1991, 9, 85-102.

60 C. Tunsu, C. Ekberg, M. Foreman and T. Retegan, Solvent Extr. Ion Exch., 2014, 32, 650-668.

61 N. K. Batchu, T. Vander Hoogerstraete, D. Banerjee and K. Binnemans, Sep. Purif. Technol., 2017, 174, 544-553.

62 B. Gupta, P. Malik and A. Deep, Solvent Extr. Ion Exch., 2003, 21, 239-258.

63 Y. A. El-Nadi, J. Rare Earths, 2010, 28, 215-220.

64 M. L. P. Reddy, R. Luxmi Varma, T. R. Ramamohan, S. K. Sahu and V. Chakravortty, Solvent Extr. Ion Exch., 1998, 16, 795-812.

65 D. F. Peppard, J. P. Faris, P. R. Gray and G. W. Mason, J. Phys. Chem., 1953, 57, 294-301.

66 J. S. Kim, B. N. Kumar, S. Radhika, M. L. Kantam and B. R. Reddy, Int. J. Miner. Process., 2012, 112-113, 37-42.

67 D. Li and C. Wang, Hydrometallurgy, 1998, 48, 301-312.

68 A. Fortuny, M. T. Coll, C. S. Kedari and A. M. Sastre, J. Chem. Technol. Biotechnol., 2014, 89, 858-865.

69 T. E. Furia, in CRC Handbook of Food Additives, ed. C. Press, CRC Press, Boca Raton, Florida, 1972.

70 G. Schwarzenbach, Analyst, 1955, 80, 713-729.

71 T. Liu, Y. H. Zhang, H. Y. Shao and X. G. Li, Langmuir, 2003, 19, 7569-7572.

72 A. Bassano, V. Buscaglia, M. Sennour, M. T. Buscaglia, M. Viviani and P. Nanni, J. Nanopart. Res., 2010, 12, 623633.

73 F. V. P. Blondet and T. Guibal, in Ion Exch. Solvent Extr., CRC Press, Boca Raton, Florida, 2007, pp. 151-292.

74 S. Yin, W. Wu, X. Bian, Y. Luo and F. Zhang, Ind. Eng. Chem. Res., 2013, 52, 8558-8564.

75 S. Yin, W. Wu, X. Bian and F. Zhang, Hydrometallurgy, 2013, 131-132, 133-137.

76 A. Kiyotaka, N. Masaharu and K. Haruo, Bull. Chem. Soc. Jpn., 1985, 58, 1543-1550.

77 M. Bauer and C. Gastl, Phys. Chem. Chem. Phys., 2010, 12, 5575-5584. 